\title{
Parachute Models Used in the Mars Science Laboratory Entry, Descent, and Landing Simulation
}

\author{
Juan R. Cruz, ${ }^{1}$ David W. Way, ${ }^{2}$ Jeremy D. Shidner, ${ }^{3}$ Jody L. Davis, ${ }^{4}$ Richard W. Powell ${ }^{5}$ \\ NASA Langley Research Center, Hampton, Virginia, 23681 \\ Devin M. Kipp, ${ }^{6}$ Douglas S. Adams, ${ }^{7}$ Anita Sengupta ${ }^{8}$ \\ Jet Propulsion Laboratory, Pasadena, California, 91109 \\ and \\ Al Witkowski, ${ }^{9}$ Mike Kandis ${ }^{10}$ \\ Pioneer Aerospace, South Windsor, Connecticut, 06074
}

\begin{abstract}
An end-to-end simulation of the Mars Science Laboratory (MSL) entry, descent, and landing (EDL) sequence was created at the NASA Langley Research Center using the Program to Optimize Simulated Trajectories II (POST2). This simulation is capable of providing numerous MSL system and flight software responses, including Monte Carlo-derived statistics of these responses. The MSL POST2 simulation includes models of EDL system elements, including those related to the parachute system. Among these there are models for the parachute geometry, mass properties, deployment, inflation, opening force, area oscillations, aerodynamic coefficients, apparent mass, interaction with the main landing engines, and offloading. These models were kept as simple as possible, considering the overall objectives of the simulation. The main purpose of this paper is to describe these parachute system models to the extent necessary to understand how they work and some of their limitations. A list of lessons learned during the development of the models and simulation is provided. Future improvements to the parachute system models are proposed.
\end{abstract}

Aerospace Engineer, Atmospheric Flight and Entry Systems Branch, Juan.R.Cruz@NASA.gov, AIAA Member. Aerospace Engineer, Atmospheric Flight and Entry Systems Branch, David.W.Way@NASA.gov, AIAA Member. Aerospace Engineer, Atmospheric Flight and Entry Systems Branch, Binera, Inc., Yorktown, Virginia, Jeremy.D.Shidner@NASA.gov, AIAA Member.

4 Aerospace Engineer, Atmospheric Flight and Entry Systems Branch, Jody.L.Davis@NASA.gov, AIAA Member.

5 Aerospace Engineer, Atmospheric Flight and Entry Systems Branch, Analytical Mechanics Associates, Inc., Hampton, Virginia, Richard.W.Powell@NASA.gov, AIAA Associate Fellow.

6 Systems Engineer, EDL Systems and Advanced Technologies Group, Devin.M.Kipp@JPL.NASA.gov, AIAA Member.

7 Senior Systems Engineer, Spacecraft Structures and Dynamics Group, Douglas.S.Adams@JPL.NASA.gov, AIAA Member.

8 Systems Engineer, EDL Systems and Advanced Technologies Group, Anita.Sengupta@JPL.NASA.gov, AIAA Member.

9 Director of Engineering Operations, Al.Witkowski@ZodiacAerospace.com, AIAA Associate Fellow.

${ }^{10}$ Engineering Lead Analyst, Mike.Kandis@ZodiacAerospace.com, AIAA Member. 


\section{Nomenclature}

\begin{tabular}{|c|c|c|c|}
\hline \multirow{3}{*}{$\begin{array}{l}C_{D_{0}} \\
C_{m_{0}}\end{array}$} & $=$ parachute drag coefficient & $K_{A O M}$ & $=$ area oscillations multiplier \\
\hline & $=$ parachute pitching moment coefficient & $K_{A p p}$ & $=$ apparent mass coefficient \\
\hline & (total/axisymmetric) about the & $K_{I}$ & $=$ inflation multiplier \\
\hline \multirow[t]{2}{*}{$C_{N}$} & $\begin{aligned} & \text { suspension lines confluence point } \\
= & \text { parachute normal force coefficient }\end{aligned}$ & $K_{\text {Int }}$ & $\begin{aligned}= & \text { interpolation factor for the static } \\
& \text { aerodynamic coefficients }\end{aligned}$ \\
\hline & $=\stackrel{\text { (total } / \text { axisymmetric })}{\text { parachute tangential force coefficient }}$ & $K_{\text {MLEI }}$ & $\begin{aligned} &= \text { main landing engines interaction } \\
& \text { multiplier }\end{aligned}$ \\
\hline $\begin{array}{l}C_{T} \\
C_{X}\end{array}$ & $=$ opening load factor & $K_{\text {Off }}$ & $=$ offloading multiplier \\
\hline \multirow[t]{2}{*}{$c_{T B L}$} & $=$ coefficient of viscous damping for the & $L_{R}$ & $=$ single riser length \\
\hline & $\begin{aligned} & \text { triple bridle legs (each) } \\
= & \text { aeroshell diameter }\end{aligned}$ & $L_{S}$ & $=$ suspension lines length \\
\hline $\begin{array}{l}D_{A S} \\
D_{B}\end{array}$ & $=$ band diameter & $L_{T B L}$ & $\begin{aligned}= & \text { unstretched (as-built) triple bridle leg } \\
& \text { length (each) }\end{aligned}$ \\
\hline$D_{D}$ & $=$ disk diameter & $\left(I_{x x}\right)_{C o M}$ & $=$ parachute mass \\
\hline $\begin{array}{l}D_{P} \\
D_{V c}\end{array}$ & $\begin{array}{l}=\text { projected diameter } \\
=\text { constrained vent diameter }\end{array}$ & & $\begin{array}{l}\text { moments of inertia about its center of } \\
\text { mass }\end{array}$ \\
\hline \multirow{2}{*}{$\begin{array}{l}D_{V u} \\
D_{0}\end{array}$} & $=$ unconstrained vent diameter & $k_{T B L}$ & $=$ spring constant for the triple bridle legs \\
\hline & $=$ parachute nominal (reference) diameter & & (each) \\
\hline \multirow[t]{2}{*}{$\left(D_{0}\right)_{\text {Des }}$} & $=$ parachute nominal (reference) diameter & $\begin{array}{l}M \\
M E F\end{array}$ & $\begin{array}{l}=\text { Mach number } \\
=\text { Mach Efficiency Factor }\end{array}$ \\
\hline & used in the calculation of $F_{F I, D e s}$ only & $m_{A p p}$ & $=$ apparent mass \\
\hline $\mathbf{F}_{B}$ & $=$ buoyancy force vector & $m_{P}$ & $=$ parachute mass \\
\hline \multirow[t]{2}{*}{$F_{B}$} & magnitude of the buoyancy force & $N_{\text {gores }}$ & $=$ number of gores (suspension lines) \\
\hline & vector, $\left|\mathbf{F}_{B}\right|$ & $n_{I}$ & $=$ exponent in the inflation prescribed \\
\hline$F_{D F L L}$ & $=$ design flight limit load & & area growth power function \\
\hline$F_{T B L}$ & $=$ force on a triple bridle leg & $q_{\infty}$ & $=$ dynamic pressure \\
\hline$F_{F I}$ & $\begin{aligned}= & \text { parachute aerodynamic force at first } \\
& \text { full inflation }\end{aligned}$ & $r_{M L E I}$ & $\begin{array}{c}=\text { radius of the cylinder used in the main } \\
\text { landing engines interaction model }\end{array}$ \\
\hline \multirow[t]{2}{*}{$F_{F I, D e s}$} & $\begin{array}{r}=\text { design parachute aerodynamic force at } \\
\text { first full inflation (used for comparison } \\
\text { against the design flight limit load }\end{array}$ & $\mathbf{R}_{P, D S}$ & $\begin{array}{l}=\text { descent stage center of mass position } \\
\text { vector with respect to the parachute } \\
\text { apex }\end{array}$ \\
\hline & $\left.F_{D F L L}\right)$ & $r_{P, D S}$ & $=$ radial component of the descent stage \\
\hline$F_{s d}$ & $\begin{aligned}= & \text { force generated by a spring-damper } \\
& \text { system }\end{aligned}$ & & $\begin{array}{l}\text { center of mass position vector, } \mathbf{R}_{P, D S}, \\
\text { with respect to the parachute apex }\end{array}$ \\
\hline \multirow{2}{*}{$\begin{array}{l}g_{\text {Mars }} \\
H_{B}\end{array}$} & $=$ Mars acceleration of gravity & $S_{B}$ & $=$ band area \\
\hline & band height & $S_{D}$ & disk area \\
\hline$H_{G}$ & gap height & $S_{G}$ & $=$ gap area \\
\hline \multirow[t]{3}{*}{$H_{T B}$} & $=$ distance between the triple bridle & $S_{V_{c}}$ & $=$ constrained vent area \\
\hline & confluence point and attachment points & $S_{V u}$ & $=$ unconstrained vent area \\
\hline & & $S_{0}$ & $\begin{array}{l}=\text { parachute nominal (reference) area } \\
=\text { narachute nominal (reference) }\end{array}$ \\
\hline$h_{M L E I}$ & $\begin{aligned}= & \text { height of the cylinder used in the main } \\
& \text { landing engines interaction model }\end{aligned}$ & & used in the calculation of $F_{F I, \text { Des }}$ only \\
\hline$h_{P, D S}$ & $\begin{aligned}= & \text { height component of the descent stage } \\
& \text { center of mass position vector, } \mathbf{R}_{P, D S}, \\
& \text { with respect to the parachute apex }\end{aligned}$ & $T\left[\varepsilon_{\text {low }}\right.$ & $\begin{array}{c}\left.\varepsilon_{\text {mode }}, \varepsilon_{\text {upper }}\right]=\text { random variable using a } \\
\text { triangular distribution; lower limit } \\
\varepsilon_{\text {lower }} \text {, mode } \varepsilon_{\text {mode }} \text {, upper limit } \varepsilon_{\text {upper }}\end{array}$ \\
\hline
\end{tabular}




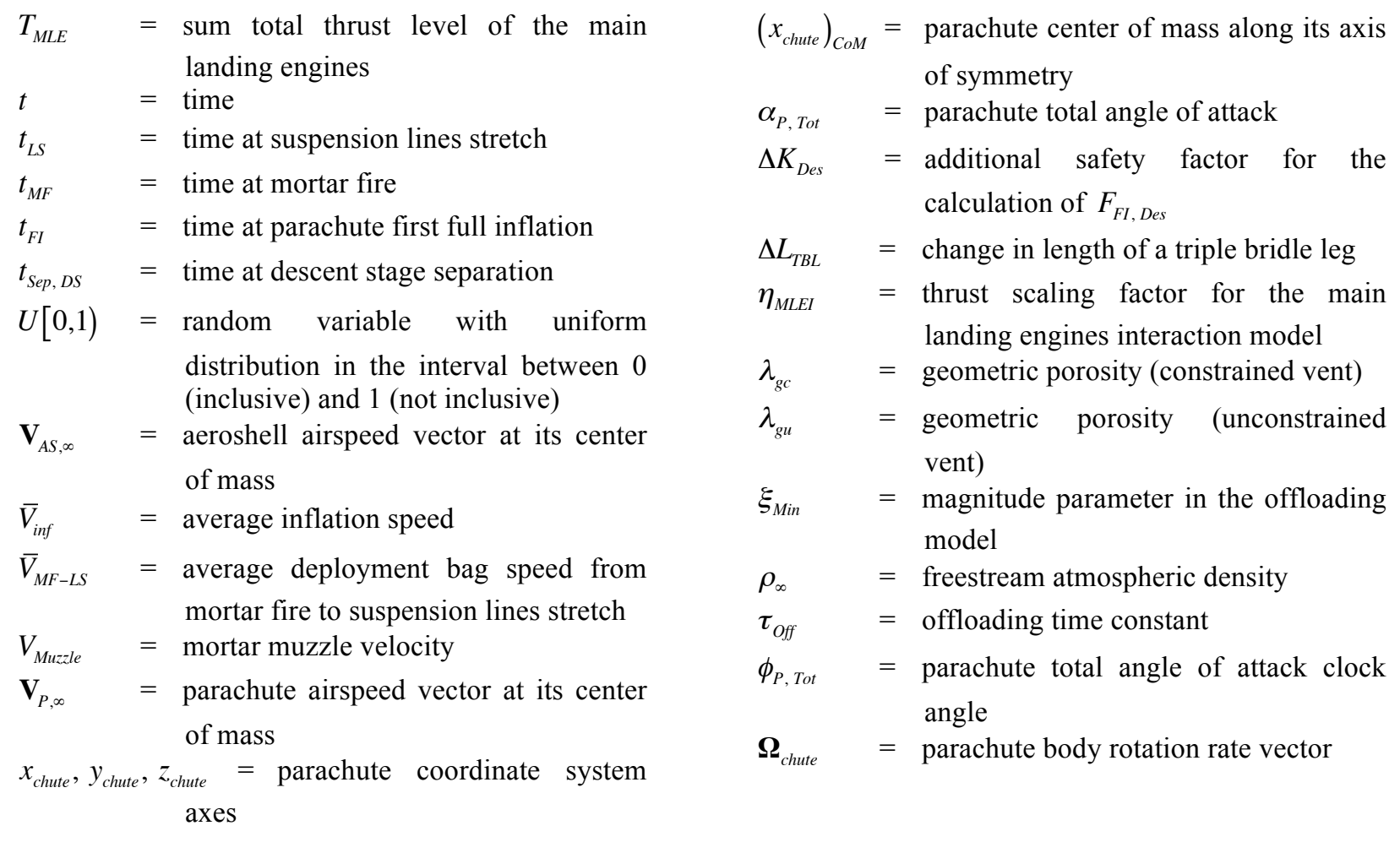

\section{Introduction}

N end-to-end simulation of the Mars Science Laboratory (MSL) entry, descent, and landing (EDL) sequence ${ }^{1}$ A was created at the NASA Langley Research Center using the Program to Optimize Simulated Trajectories II (POST2). ${ }^{2,3}$ This simulation is capable of providing numerous MSL system and flight software responses, including Monte Carlo-derived statistics of these responses. The MSL POST2 simulation (referred henceforth as "simulation") provides the highest fidelity environment for assessing flight dynamic performance of the MSL spacecraft, and is the primary venue for verification and validation of flight dynamics requirements. The simulation includes numerous models of the various systems, including those related to the parachute system. This paper describes these parachute system models.

The primary purposes of the parachute models within the simulation are to determine:

- parachute opening forces,

- aeroshell trajectory (e.g., velocity and altitude vs. time),

- aeroshell dynamics (e.g., translational accelerations, rotational rates and accelerations), and

- forces imposed by the parachute on the aeroshell.

Parachute models were kept as simple as possible while still fulfilling their primary purposes as listed above. Thus, not all aspects of the parachute, its operation, and behavior are modeled in detail. For example, the trajectory and dynamics of the parachute deployment bag from mortar fire to suspension lines stretch are not modeled. Models were tuned to the available experimental data. Many of the models are empirical, and make use of data from previous similar missions to Mars (e.g., the Viking and Phoenix landers), and MSL-specific data. Thus, although the approach used in these models may be adapted to other missions, their use and the values of numerical constants in them should be examined critically before use.

In a companion paper, ${ }^{4}$ a reconstruction of the MSL parachute performance on Mars is presented and compared to some of the parachute models and results from the simulation. The descriptions of the MSL parachute system and its operation, as presented herein, are also included in reference 4. 


\section{Parachute Decelerator System}

\section{A. System Description}

The Mars Science Laboratory used a single, supersonically-deployed disk-gap-band (DGB) parachute with a nominal diameter $\left(D_{0}\right)$ of $21.35 \mathrm{~m}$ (see figures 1 and 2). This DGB parachute was similar in geometric proportions to those used by the Viking missions to Mars, ${ }^{5}$ but 33 percent larger in nominal diameter, making it the largest parachute that has been deployed on Mars.

The disk was fabricated from two types of fabric: a ripstop polyester of nominal $1.4 \mathrm{oz} / \mathrm{yd}^{2}$ areal weight manufactured to a Pioneer Aerospace specification on the crown, and a ripstop nylon of nominal $1.1 \mathrm{oz} / \mathrm{yd}^{2}$ areal weight per Parachute Industry Association specifications (PIA-C-7020B Type I for the white nylon fabric, PIA-C-7020C, Type I for the orange nylon fabric - see figure 2). All fabric on the disk was placed in the bias orientation. The various fabrics can be clearly seen in figure 2. The band was fabricated from the same ripstop nylon fabrics described above placed in the block orientation. The suspension lines were fabricated from Technora T221 braided cord. All other textile structural elements were fabricated from Kevlar 29. The confluence fitting (located at the single riser to triple bridle confluence point) was fabricated using titanium TI-6AL-4V plate and A286 steel bolts.

Deployment was effected by a mortar ${ }^{6}$ with a muzzle velocity of approximately $39 \mathrm{~m} / \mathrm{s}$. The parachute was qualified to be deployed at Mach numbers up to 2.3, with a not-to-exceed peak parachute aerodynamic opening force (design flight limit load, $\left.F_{D F L L}\right)$ of $289 \mathrm{kN}(65,000 \mathrm{lb}){ }^{7}$

\section{B. Concept of Operation}

The MSL EDL concept of operation, starting from just prior to parachute deployment, is shown in figure 3. Nominal operation proceeds as follows:

- During entry the MSL aeroshell is balanced such that its center of mass is offset from its axis of symmetry. This causes the aeroshell to trim at a total angle of attack of approximately $16^{\circ}$. This nonzero total angle of attack trim angle produces lift, which allows MSL's entry to be guided by banking the aeroshell. However, for parachute deployment, a near-zero total angle of attack is desired. Just prior to parachute deployment a series of six balance masses are ejected from the aeroshell at two-second intervals. The ejection of these balance masses brings the center of mass of the aeroshell to a location near its axis of symmetry, causing the aeroshell to fly at a total angle of attack of nominally less than five degrees - an acceptable value for supersonic parachute deployment. Deploying the parachute at a low angle of attack also reduces the aeroshell dynamic motions and minimizes side forces on the aeroshell during inflation. Concurrently with the ejection of the balance masses, the reaction control system (RCS) rolls the aeroshell to the bank angle required for later radar operation purposes. The ejection of the balance masses, and the rolling of the aeroshell, is known as the Straighten Up and Fly Right (SUFR) maneuver. During the SUFR maneuver the RCS is used to damp pitch and yaw oscillations.

- After the SUFR maneuver is completed, the RCS is inhibited, the mortar is fired, and the parachute is deployed. Mortar fire is controlled by a velocity magnitude trigger. ${ }^{8}$

- Parachute deployment and inflation occurs during a time interval of approximately $2 \mathrm{~s}$ after mortar fire.

- Ten seconds after mortar fire the RCS is re-enabled to damp aeroshell oscillations if necessary.

- Fifteen to 30 seconds after mortar fire the heatshield separation conditions are met. Heatshield separation is controlled by a "dot product" velocity trigger ${ }^{8}$ set to ensure an aeroshell Mach number less than 0.8 at separation. The RCS is inhibited just prior to heatshield separation.

- Three seconds after heatshield separation the RCS is re-enabled to damp aeroshell oscillations if necessary.

- The aeroshell descends under parachute for 40 to $180 \mathrm{~s}$ until the descent stage separation conditions are met. Descent stage separation is commanded by an attitude/velocity trigger. ${ }^{8}$ The RCS is inhibited for a final time immediately preceding descent stage separation.

- The descent stage free falls unpowered for $1 \mathrm{~s}$, followed by another $0.2 \mathrm{~s}$ for main landing engines (MLE) warm-up, and an additional $0.8 \mathrm{~s}$ for de-tumbling and turning into the initial attitude for powered flight. One of the powered descent stage's initial objectives is to perform a divert maneuver to avoid both short- and long-term re-contact with the backshell and parachute. The rover is placed on the surface of Mars by the powered descent stage operating in the sky crane mode.

In figure 4 most of the parachute models described in this paper (left hand side) are shown vs. the EDL events (right hand side). The timeline is shown vertically from top to bottom. All times in figure 4 are approximate. 


\section{Modeling}

\section{A. Basic Modeling Assumptions}

The simulation models the aeroshell and parachute as two rigid bodies as shown in figure 5. The parachute and single riser is modeled as one rigid body with its own set of mass properties (section III.D) and aerodynamic coefficients (section III.I). This rigid parachute/single riser body (referred henceforth as "parachute") is connected to the aeroshell by a triple bridle. The single riser and triple bridle connect at the confluence fitting. This confluence fitting is not modeled explicitly as an independent mass element - its presence in this model is just geometric. The legs of the triple bridle are modeled as massless, tension-only, linear spring-dampers (section III.C). The parachute's wind angles (i.e., angle of attack, angle of sideslip, and/or equivalents) and dynamic pressure are calculated at the parachute's center of mass (see section V.B for recommendations regarding improvements in the calculation of these wind angles). The Mach number used for the parachute models, however, is that of the aeroshell's center of mass. This is done to eliminate unrealistic parachute Mach number oscillations arising from interactions between the elastic triple bridle and the area oscillations model. See section III.G for more details related to this Mach number replacement. Values for several of the system geometric parameters are presented in section III.B.

\section{B. Geometric Parameters}

Key geometric parameters of the parachute system are shown in table 1 and figure 6 . Note that the nominal (reference) parachute diameter, $D_{0}$, has an uncertainty associated with it. This uncertainty is used to randomly perturb the specific value of $D_{0}$ used for a given Monte Carlo trial in the simulation. Also note that the nominal parachute diameter, with perturbation, is used to calculate the nominal (reference) parachute area, $S_{0}$. It is these perturbed values of $D_{0}$ and $S_{0}$ that are used in the simulation for calculations involving the trajectory, flight dynamics, and the parachute aerodynamic force at first full inflation, $F_{F I}$. An additional, unperturbed set, of nominal parachute diameter and area, $\left(D_{0}\right)_{D e s}$ and $\left(S_{0}\right)_{D e s}$, are used for the calculation of the design parachute aerodynamic force at first full inflation, $F_{F I, D e s}$, only, which is then used for comparison against the fixed design flight limit load, $F_{D F L L}$. The difference between $F_{F I}$ and $F_{F I, D e s}$ is discussed in section III.F. As-built geometric parameters of the MSL parachute are provided in table 2.

\section{Elastic Properties}

The only elastic elements in the parachute model are the triple bridle legs; the riser and parachute are assumed to be a single rigid unit. The legs of the triple bridle are modeled as massless, tension-only, linear spring-dampers. In this model the force on each triple bridle leg is calculated from:

Where,

$$
\begin{gathered}
F_{s d}=k_{T B L} \Delta L_{T B L}+c_{T B L} \frac{d\left(\Delta L_{T B L}\right)}{d t} \\
\text { If } F_{s d}>0 \text { then } F_{T B L}=F_{s d} \text { else } F_{T B L}=0 \text { endif }
\end{gathered}
$$

$F_{\text {sd }}$ is the force generated by a spring-damper system,

$k_{T B L}$ is the spring constant (each leg),

$c_{T B L}$ is the coefficient of viscous damping (each leg),

$\Delta L_{T B L}$ is the change in length of a triple bridle leg,

$t$ is time, and

$F_{T B L}$ is the force on a triple bridle leg.

The modeled elastic properties for each triple bridle leg are:

$$
\begin{aligned}
k_{T B L} & =1.712 \times 10^{7} \mathrm{~N} / \mathrm{m} \\
c_{T B L} & =10,900 \mathrm{~N} \bullet \mathrm{s} / \mathrm{m}
\end{aligned}
$$

The coefficient of viscous damping represents one percent structural damping at $5 \mathrm{~Hz}$. The unstretched length of the triple bridle legs is given in table 1. These elastic properties become active at suspension lines stretch and are constant through the simulation. 


\section{Mass Properties}

As mentioned in section III.A and shown in figure 5, the parachute downstream of the confluence fitting is modeled as a single rigid body. The nominal mass properties of the parachute were calculated using a three-dimensional computer aided design (CAD) model using the as-measured masses of the components comprising the parachute, and an assumed inflated shape. This CAD model is axisymmetric. Thus, the parachute's center of mass is on its axis of symmetry, the mass products of inertia perpendicular to the axis of symmetry are identical, and the mass products of inertia are zero. The nominal mass properties are given in table 3 . For simulation Monte Carlo trials the mass properties were perturbed. The total perturbations were estimated using both correlated (i.e., perturbations due to assumed changes in the parachute inflated geometry) and uncorrelated components. A complete description of the parachute mass properties perturbations and how they were calculated is beyond the scope of this paper. The mass properties of the parachute become active at suspension lines stretch. There is no ramp-up of the mass properties during inflation.

A portion of the parachute system mass properties (e.g., triple bridle, sabot) remains accounted for in the mass properties of the aeroshell. This portion of the parachute system mass properties is a small fraction of the aeroshell mass properties. Because of this, perturbations of their values are not necessary for Monte Carlo trials.

\section{E. Mortar Recoil Force}

The time at which the mortar recoil force starts is denoted as the mortar firing time for the purpose of this model. The mortar recoil force is imparted on the aeroshell as the parachute pack is ejected by the mortar at high speed. This mortar recoil force is modeled as a time-varying force of short duration. The mortar recoil force acts along the aeroshell axis of symmetry in the flight direction. No random perturbation of the mortar recoil force is included in this model. This model was created using data provided by General Dynamics Ordnance and Tactical Systems obtained from the MSL mortar qualification tests.

\section{F. Deployment, Inflation, and Opening Forces}

In this section the models for deployment, inflation, and opening forces are described. Because these models are closely interrelated, they are described in the same section. The models described in this section are empirical, and derived principally from Viking, ${ }^{9-13}$ Phoenix, ${ }^{14}$ and MSL test data. They are specific to MSL. Among the assumptions made in their development are that the parachute is deployed by a mortar while in supersonic flight, and that inflation is of the infinite-mass type.

Deployment and Inflation

For the purposes of this document, deployment and inflation are defined as follows:

Deployment. The events occurring from mortar firing at time $t=t_{M F}$, to suspension lines stretch at time $t=t_{L S}$, that is $t_{M F} \leq t \leq t_{L S}$. For modeling purposes, the time at mortar firing, $t_{M F}$, is defined as the time at which the mortar recoil force starts. Also for modeling purposes, the time at suspension lines stretch, $t_{L S}$, is defined as the time at which the skirt of the canopy starts to emerge from the deployment bag. Except for the mortar recoil force, the parachute is not explicitly modeled during the time interval from mortar firing up to (but not including) suspension lines stretch. The time at suspension lines stretch, in seconds, is calculated from the equation

$$
t_{L S}=t_{M F}+\frac{H_{T B}+L_{R}+L_{S}}{\bar{V}_{M F-L S}}
$$

The time at mortar fire, $t_{M F}$, must be entered in seconds in equation (3). The length $\left(H_{T B}+L_{R}+L_{S}\right)$ is that of the stretched-out parachute at suspension lines stretch, and must be entered in meters in equation (3). The numerical value for this length can be determined from the data in tables 1 and 2 . The parameter $\bar{V}_{M F-L S}$ is the average deployment bag speed from mortar fire to suspension lines stretch, and must be entered in meters per second in equation (3). Its value depends on the mortar muzzle velocity, $V_{\text {Muzzle }}$, as given by

$$
\bar{V}_{M F-L S}=V_{\text {Muzzle }} \cdot[0.875+(0.060 \bullet U[0,1)-0.030)]
$$

\footnotetext{
* The quantity $U[0,1)$ is a random variable with uniform distribution in the interval between 0 (inclusive) and 1 (not inclusive). Unless specifically called for, the value of $U[0,1)$ is not reused.
} 
The muzzle velocity is given by

$$
V_{\text {Muzle }}=39 \mathrm{~m} / \mathrm{s}+[4 \mathrm{~m} / \mathrm{s} \bullet U[0,1)-2 \mathrm{~m} / \mathrm{s}]
$$

Note that $\bar{V}_{M F-L S}$ and $V_{M u z z l e}$ are perturbed (random) parameters; they are calculated once for a given Monte Carlo trial. Equations (4) and (5) include both the nominal values (i.e., 0.875 in equation (4) and $39 \mathrm{~m} / \mathrm{s}$ in equation (5)), and the perturbations (i.e., the quantities in parenthesis involving the $U[0,1)$ term) to be used in Monte Carlo trials. The calculation of the time from mortar fire to suspension lines stretch described by equations (3) to (5) is empirical and highly simplified. The accuracy of this calculation could be improved - see section V.A.

At suspension lines stretch, the parachute "appears" in the simulation and its aerodynamic and inertial characteristics become active. This activation of the parachute occurs with the following initial conditions at $t=t_{L S}$.

- The parachute's airspeed vector at its center of mass, $\mathbf{V}_{P, \infty}$, is

$$
\mathbf{V}_{P, \infty}=\mathbf{V}_{A S, \infty}
$$

where $\mathbf{V}_{A S, \infty}$ is the aeroshell's airspeed vector at its center of mass.

- The parachute appears at a perturbed (random) total angle of attack, $\alpha_{P, T o t}$, and total angle of attack clock angle, $\phi_{P, T o t}$ determined from

$$
\begin{gathered}
\alpha_{P, \text { Tot }}=T\left[0^{\circ}, 8^{\circ}, 12^{\circ}\right] \\
\phi_{P, \text { Tot }}=360^{\circ} \cdot U[0,1)-180^{\circ}
\end{gathered}
$$

Note that $\alpha_{P, T o t}$ and $\phi_{P, T o t}$ are calculated once for a given simulation. Equations (7) and (8) include the perturbations to be used in Monte Carlo trials. In calculating $\mathbf{V}_{P, \infty}, \alpha_{P, T o t}$, and $\phi_{P, \text { Tot }}$ per equations (6), (7), and (8), it is assumed that the wind at the parachute's center of mass is the same as that at the aeroshell's center of mass. This is not exactly correct, but is accepted as a modeling approximation. If there is a wind gradient there can be a small difference in the wind at the two locations. In the case of MSL the high airspeed at parachute deployment, and the relatively small distance between the parachute and aeroshell centers of mass, makes this approximation reasonable.

- The parachute body rotation rate vector is zero: $\Omega_{\text {chute }}=0$.

- The parachute is placed in a position consistent with its wind angles (i.e., $\alpha_{P, T o t}$ and $\phi_{P, T o t}$ as defined above), the requirement that its axis of symmetry pass through the center of the triangle defined by the triple bridle attachment points on the aeroshell, and the requirement that none of the triple bridle legs be stretched beyond their unloaded length. Note that this positioning allows one or two of the triple bridle legs to be slack.

The simulation implementation of the parachute activation model achieves the same objective as described above, but does so in terms of different variables.

The triple bridle elastic properties (section III.C) and mass properties (III.D) become active (i.e., without ramp-up during inflation) at $t=t_{L S}$. The aerodynamic properties (sections III.H and III.I) become active at $t=t_{L S}$, and ramp-up as described in the opening forces model described below.

Inflation. The events occurring from suspension lines stretch, $t_{L S}$, up to, but not including, the first full inflation, $t_{F I}$, of the canopy. That is, $t_{L S} \leq t<t_{F I}$. The time at first full inflation, in seconds, is calculated from the equation

$$
t_{F I}=t_{L S}+\frac{D_{0}}{\bar{V}_{i n f}}
$$

where,

$$
\bar{V}_{\text {inf }}=29.9 \mathrm{~m} / \mathrm{s}+[7.0 \mathrm{~m} / \mathrm{s} \bullet U[0,1)-3.5 \mathrm{~m} / \mathrm{s}]
$$

† The quantity $T\left[0^{\circ}, 8^{\circ}, 12^{\circ}\right]$ is a random variable with triangular distribution whose lower limit is $0^{\circ}$, its mode is $8^{\circ}$, and its upper limit is $12^{\circ}$. Unless specifically called for, the value of $T$ is not reused. 
The time at suspension lines stretch, $t_{L S}$, must be entered in seconds in equation (9). The nominal parachute diameter, $D_{0}$, must be entered in meters in equation (9). Note that $D_{0}$ must include the perturbation defined in table 1. The parameter $\bar{V}_{i n f}$ is the average inflation speed, and must be entered in meters per second in equation (9). Equation (10) includes both the nominal value of $\bar{V}_{\text {inf }}$ (i.e., $29.9 \mathrm{~m} / \mathrm{s}$ ), and the perturbation (i.e., the quantity in parenthesis involving the $U[0,1)$ term) used to calculate the value of $\bar{V}_{\text {inf }}$ for Monte Carlo trials.

Opening Forces During Inflation

The forces and moments generated by the parachute during deployment are a small fraction of those encountered during inflation. Because of this, parachute deployment forces (except for the mortar recoil force) and moments are assumed to be zero in the present model. Parachute aerodynamic forces and moments during inflation are controlled by a time-dependent nondimensional variable, $K_{I}$, that is used as a multiplier for the parachute tangential, normal, and pitching moment coefficients $\left(C_{T}, C_{N}\right.$, and $C_{m_{o}}$, respectively). This multiplier is used during the time interval from $t_{L S}$ to $t_{F I}$ as shown in figure 7 and defined by

$$
\begin{gathered}
\text { For } t_{L S} \leq t<t_{F I} \text { (inflation): } K_{I}=C_{X}\left(\frac{t-t_{L S}}{t_{F I}-t_{L S}}\right)^{n_{I}} \\
C_{X}=1.407 \\
n_{I}=4
\end{gathered}
$$

Equation (11) describes a prescribed area growth model where $C_{X}$ is the opening load factor and $n_{I}$ is the exponent of the inflation prescribed area growth power function. The value of $C_{X}$ is dependent on the drag coefficient model; thus, it is valid only for the drag coefficient and static aerodynamic coefficients model described in sections III.H and III.I. Note that for $t \geq t_{F I}$ the calculation of aerodynamic forces generated by the parachute proceed in the usual manner without using $K_{I}$.

Peak Opening Forces

In this model the first full inflation is assumed to be coincident with the inflation first peak force. The parachute aerodynamic force at first full inflation, $F_{F I}$, is calculated from

$$
F_{F I}=q_{\infty} S_{0} C_{X}\left(C_{T}^{2}+C_{N}^{2}\right)^{\frac{1}{2}}
$$

where the values of the dynamic pressure, $q_{\infty}, C_{T}$, and $C_{N}$ are those at $t=t_{F I}$. Note that the values of $C_{T}$ and $C_{N}$ in equation (12) need to incorporate the perturbations described in section III.I, be determined at the appropriate total angle of attack, and have incorporated the Mach Efficiency Factor described in section III.H. For comparison to the design flight limit load ( $F_{D F L L}$, a fixed value), he design parachute aerodynamic force at first full inflation, $F_{F I, D e s}$, occurs at first full inflation, $t=t_{F I}$, and is calculated from the equation

$$
F_{F I, D e s}=\left(1+\Delta K_{\text {Des }}\right) q_{\infty}\left(S_{0}\right)_{\text {Des }} C_{X}\left(C_{D_{0}}\right)_{\text {High }}
$$

where $\left(S_{0}\right)_{D e s}$ is an upper bound estimate of the nominal area (see table 1), and $\left(C_{D_{0}}\right)_{H i g h}$ is the upper bound of the drag coefficient model (section III.H). The values of $q_{\infty}$ and $\left(C_{D_{0}}\right)_{H i g h}$ to be used in equation (13) are those at $t=t_{F I}$. The value of $\left(C_{D_{0}}\right)_{H i g h}$ is determined using the Mach number at $t=t_{F I}$. The leading term in equation (13), $\left(1+\Delta K_{D e s}\right)$, is an additional multiplier for the calculation of $F_{F I, D e s}$ to add conservatism to the calculation of the design peak opening force. For the final set of simulations conducted in support of the MSL EDL, the value of $\Delta K_{D e s}$ was set to zero. The value of $F_{F I, D e s}$ is intended to be a conservative estimate of the parachute aerodynamic force at first full inflation on the parachute. Note that it uses conservative values of the nominal area (i.e., $\left(S_{0}\right)_{D e s}$ as compared to $\left.S_{0}\right)$ and the drag coefficient (i.e., $\left(C_{D_{0}}\right)_{H i g h}$ ). The MSL parachute was

\# This value of $F_{F I}$ can be exceeded for $t>t_{F I}$ due to area oscillations. See section III.G. 
qualified by test to a design flight limit load, $F_{D F L L}$, of $289 \mathrm{kN}(65,000 \mathrm{lb}){ }^{7}$ For the results of a given set of simulation Monte Carlo trials (i.e., a set of entry conditions targeting a specific landing location) to be considered acceptable, the $99^{\text {th }}$ percentile value of $F_{F I, D e s}$ could not exceed $F_{D F L L}$.

\section{G. Area Oscillations}

Previous flight experience with DGB parachutes indicates that at Mach numbers $(M)$ above 1.4, large parachute force oscillations occur after the first inflation peak force (see, for example, reference 11). These force oscillations are at least partially related to changes in the projected area of the parachute, as the parachute undergoes collapse and re-inflation cycles, and are commonly referred to as area oscillations. A significant contributor to these area oscillations is interaction between the aeroshell wake and parachute flow fields. Because the MSL parachute was to deploy its parachute at a Mach number greater than 1.4, and perhaps spend a significant amount of time in this flight regime (sufficient for several area oscillations), it was deemed necessary to include a parachute area oscillations model in the simulation. Including such a model was thought to improve the fidelity of the aeroshell dynamics results obtained from the simulation.

The area oscillations model described here is synthetic, in the sense that it simulates area oscillations without modeling the underlying physics (which are poorly understood). It was, however, tuned to the available data from the Viking BLDT AV-4 flight test ${ }^{11}$ and the Phoenix Mars flight. ${ }^{14-16}$ The area oscillations model calculates a Mach number- and time-dependent nondimensional parameter, $K_{A O M}(M, t)$, that is used as a multiplier for the parachute tangential, normal, and pitching moment coefficients $\left(C_{T}, C_{N}\right.$, and $C_{m_{o}}$, respectively). This multiplier is used during the time interval from first full inflation, $t_{F I}$, up to the time at which the Mach number is 1.4. The value of $K_{A O M}$ was calculated by a function consisting of a randomized sinusoidal oscillatory term constrained as follows: by an exponential function to drive $K_{A O M}$ to 1.0 as the Mach number approaches 1.4, by limiting the upper value of $K_{A O M}$, and by limiting $K_{A O M}$ to positive values. A different function $K_{A O M}(M, t)$ is determined for each Monte Carlo trial. Because of interactions between the area oscillations model and the elastic modes of the parachute system (in the simulation due to the flexibility of the triple bridle), unrealistic values of the Mach number can be obtained at the parachute's center of mass due to rapid motion of the parachute, resulting in nonphysical feedback with the area oscillations and Mach Efficiency Factor (section III.G) models. Thus, the Mach number used in the area oscillations model is that of the center of mass of the aeroshell, not that for the parachute center of mass.

The equations used in the calculation of $K_{A O M}$ are given in the appendix. To illustrate the possible functional values that $K_{A O M}$ can take, two realizations are shown in figure 8 as a function time for a prescribed Mach number time history (also shown). The Mach number time history is that for the Viking BLDT AV-4 test flight, ${ }^{11}$ starting near parachute inflation first peak force. Note that the calculated values of $K_{A O M}$ exhibits a random oscillatory behavior about a value of 1.0, its magnitude decreases with $M$, and becomes equal to one at $M=1.4$.

\section{H. Drag Coefficient and Mach Efficiency Factor}

A parachute drag coefficient, $C_{D_{0}}$, model was created. This model considered the specific MSL geometry in its definition, including the effect of the longer parachute trailing distance (i.e., $10.32 \bullet D_{A S}$, see figure 6). The reference areas for $C_{D_{0}}$ are the parachute nominal areas, either $S_{0}$ or $\left(S_{0}\right)_{D e s}$, as appropriate (see sections III.B and III.F, and table 1). The parachute drag coefficient model is defined as functions of Mach number only. This model was created from an amalgamation of data including those from Viking wind tunnel tests, ${ }^{17}$ Viking BLDT flight tests, ${ }^{12,18}$ Phoenix Mars flight data, ${ }^{16}$ and MSL-specific wind tunnel tests. Low, Nominal, and High values were defined and denoted as $\left(C_{D_{0}}\right)_{\text {Low }},\left(C_{D_{0}}\right)_{\text {Nominal }}$, and $\left(C_{D_{0}}\right)_{H i g h}$, respectively. The Low and High values define bounds of uncertainty surrounding $\left(C_{D_{0}}\right)_{\text {Nominal }}$. These bounds are \pm 12.5 percent for $M \leq 1$, and increase asymptotically with Mach number for $M>1$ from \pm 12.5 percent at $M=1$ to \pm 25 percent at $M=2.6$. A graph of this $C_{D_{0}}$ model is shown in figure 9. Several features of the model can be observed. First, the model assumes that $C_{D_{0}}$ is independent of Mach number for $M \leq 0.8$. Second, a transonic drag dip occurs near $M=0.95$. This behavior has been observed in wind tunnel test data, ${ }^{17}$ and it is due to interaction between the aeroshell and parachute flow fields. Finally, after recovering from the transonic drag dip, the drag coefficient increases and peaks at a Mach number of 
approximately 1.5 , but then decreases again at higher Mach numbers. The $C_{D_{0}}$ model is only used directly in the simulation for the calculation of $F_{F I, D e s}$ (section III.F). However, it is used to define the Mach Efficiency Factor, $M E F$, model (see below) and is used to inform the static aerodynamic coefficients model (section III.I).

The Mach Efficiency Factor, MEF , is calculated from the Nominal value of the drag coefficient model by the equation

$$
M E F=\frac{\left(C_{D_{0}}\right)_{\text {Nominal }}}{\left(C_{D_{0}}\right)_{\text {Nominal } @ M=0.2}}
$$

The Mach Efficiency Factor, as a function of the Mach number, is shown in figure 10. The purpose of the $M E F$ is to serve as a scaling factor for the static aerodynamic coefficients to account for variations in their values as functions of $M$ (section III.I). The behavior of $M E F$ with respect to $M$ is similar to that described above for $C_{D_{0}}$.

As mentioned in section III.G, there is an interaction between the area oscillations model, the MEF model, and the triple bridle elastic properties, that can yield unrealistic oscillatory values of the Mach number at the parachute's center of mass due to rapid oscillations of the parachute. Thus, the values of the Mach number used with the drag coefficient and Mach Efficiency Factor models should be those of the center of mass of the aeroshell at all times.

\section{Aerodynamic Coefficients}

There are three static aerodynamic coefficients in the model created for the simulation: tangential $\left(C_{T}\right)$, normal

$\left(C_{N}\right)$, and pitch $\left(C_{m_{O}}\right)$. They are specified as functions of the total angle of attack, $\alpha_{P, T o t}$. The orientation of the forces and moments they represent are defined with respect to the total angle of attack plane as seen in figure 11, where the force vectors specified by $C_{T}$ and $C_{N}$ are in the total angle of attack plane, and the moment vector specified by $C_{m_{o}}$ is perpendicular to this plane. Because the parachute is axisymmetric, $C_{T}, C_{N}$, and $C_{m_{o}}$ are sufficient to describe the static aerodynamic coefficients of the parachute. As a set they can also be referred to as the total or axisymmetric static aerodynamic coefficients. The reference area used in their definition is $S_{0}$. The reference length used for $C_{m_{0}}$ is $D_{0}$, and its reference point is the suspension lines confluence point. As defined here the suspension lines confluence point is the imaginary confluence point the physical suspension lines would reach if they were extended upstream until they met (see figure 6). In actual construction the suspension lines do not physically meet at this point since they are grouped into risers before they reach this point. If the normal force and the pitching moment are to be applied at a location other than this reference point (e.g., the parachute's center of mass), the value of $C_{m_{o}}$ needs to be recalculated for that point.

The static aerodynamic coefficient model becomes active at suspension lines stretch and remains active thereafter (i.e., it is active for $t \geq t_{L S}$ ). As shown in figure 12, the static aerodynamic coefficients model is specified as a function of the parachute's total angle of attack, at a Mach number of 0.2. For use at other Mach numbers the static aerodynamic coefficients need to be multiplied by the Mach Efficiency Factor defined in section III.H. Note that the Mach number to be used is that of the aeroshell (see discussion on this point in sections III.G and III.H). In the simulation the parachute total angle of attack and its dynamic pressure are calculated based on the airspeed components at the center of mass of the parachute (see table 3 and figure 6). During certain time intervals, and over certain values of Mach number, the static aerodynamic coefficients need to be multiplied by other constants: $K_{I}$ during inflation (section III.F), $K_{\text {AOM }}$ during the time that area oscillations are possible (section III.G), by $K_{\text {MLEI }}$ to account with interaction with the main landing engines (section III.K), and by $K_{\text {Off }}$ to account for offloading (section III.L).

Three curves are given for each of the static aerodynamic coefficients in figure 12: Nominal, Boundary 1, and Boundary 2. The Boundary curves define an estimated uncertainty surrounding the Nominal values. A uniform uncertainty distribution between the Nominal and Boundary 1 values, and between the Nominal and Boundary 2 values, is used, with equal probability of being on either side of the Nominal value. The uncertainty boundaries are correlated. Note, for example, that the curve for Boundary 2 has the lowest value of the trim parachute total angle of attack (i.e., value of $\alpha_{P, T o t}$ for which $C_{m_{o}}$ ), and presumably provides the best parachute stability. In agreement with the general trend that higher parachute stability is associated with a lower drag coefficient, it is the $C_{T}$ curve for Boundary 2 that has the lower values. Because of this correlation between curves, an interpolated set of static aerodynamic coefficient curves for a particular Monte Carlo trial must always be on the same side of the Nominal 
curve and at the same relative distance. Such an interpolation can be accomplished by calculating an interpolation factor, $K_{I n t}$, defined by

$$
K_{\text {Int }}=2 U[0,1)-1
$$

Thus, the range of $K_{I n t}$ is $-1 \leq K_{I n t}<1$. Note that $K_{I n t}$ is calculate only once for each Monte Carlo trial. The same value of $K_{I n t}$ is used to interpolate all three static aerodynamic coefficients (i.e., $\left(C_{T}\right)_{I n t},\left(C_{N}\right)_{I n t}$, and $\left.\left(C_{m_{0}}\right)_{I n t}\right)$. An interpolated set of curves for the static aerodynamic coefficients are then calculated from

$$
\begin{gathered}
\text { If } K_{\text {Int }} \geq 0 \text { then } \\
\left(C_{T}\right)_{\text {Int }}=\left(C_{T}\right)_{\text {Nominal }}+K_{\text {Int }}\left[\left(C_{T}\right)_{\text {Boundary 1 }}-\left(C_{T}\right)_{\text {Nominal }}\right] \\
\left(C_{N}\right)_{\text {Int }}=\left(C_{N}\right)_{\text {Nominal }}+K_{\text {Int }}\left[\left(C_{N}\right)_{\text {Boundary } 1}-\left(C_{N}\right)_{\text {Nominal }}\right] \\
\left(C_{m_{O}}\right)_{\text {Int }}=\left(C_{m_{O}}\right)_{\text {Nominal }}+K_{\text {Int }}\left[\left(C_{m_{O}}\right)_{\text {Boundary 1 }}-\left(C_{m_{O}}\right)_{\text {Nominal }}\right] \\
\text { else } \\
\left(C_{T}\right)_{\text {Int }}=\left(C_{T}\right)_{\text {Nominal }}-K_{\text {Int }}\left[\left(C_{T}\right)_{\text {Boundary 2 }}-\left(C_{T}\right)_{\text {Nominal }}\right] \\
\left(C_{N}\right)_{\text {Int }}=\left(C_{N}\right)_{\text {Nominal }}-K_{\text {Int }}\left[\left(C_{N}\right)_{\text {Boundary 2 }}-\left(C_{N}\right)_{\text {Nominal }}\right] \\
\left(C_{m_{O}}\right)_{\text {Int }}=\left(C_{m_{O}}\right)_{\text {Nominal }}-K_{\text {Int }}\left[\left(C_{m_{O}}\right)_{\text {Boundary 2 }}-\left(C_{m_{O}}\right)_{\text {Nominal }}\right]
\end{gathered}
$$

The data used to create the static coefficient model was obtained during the test campaign described in reference 19. Judicious interpolation and extrapolation of these data was required to create this model.

The static aerodynamic coefficient model is related to the drag coefficient model. At each of the three trim parachute total angles of attack where the pitching moment coefficient is zero, ${ }^{\S}$ and the normal force coefficient is also zero. Thus the associated values of the drag coefficients at the trim parachute total angles of attack are $C_{D_{0}}=C_{T} \cos \alpha_{P, T o t}$. These three values of $C_{D_{0}}$ calculated from the static aerodynamic coefficients for the Boundary 2, Nominal, and Boundary 1 curves were intended to be the same as the Low, Nominal, and High values of $C_{D_{0}}$, respectively, for $M=0.2$ as determined from the drag coefficient model. An unintended small discrepancy of approximately 0.5 percent in absolute value exists between the Boundary 1/High and Boundary 2/Low values of $C_{D_{0}}$ at the trim parachute total angle of attack as determined per the above discussion. This was due to an oversight in updating models during development. However this discrepancy does not alter the fact that the drag coefficient and static coefficient models are related.

No data was available to create models for the dynamic aerodynamic coefficients (e.g., $C_{m_{q}}, C_{m_{\dot{\alpha}}}$ ). Thus, dynamic aerodynamic coefficients are not included as part of the parachute models and simulation. Doing so is the equivalent of assuming they are all zero.

\section{J. Apparent Mass}

For purposes of this paper, "apparent mass" is the term used to describe the mass of the fluid within and around the parachute that generates aerodynamic forces proportional to the parachute's accelerations (both linear and rotational). The apparent mass model described here consists of a single point mass coincident with the physical center of mass of the parachute. This apparent mass, $m_{A p p}$, is dependent on the freestream atmospheric density at the parachute's center of mass, $\rho_{\infty}$, and the parachute's nominal diameter, $D_{0}$. The apparent mass is calculated from

where $K_{A p p}$ is the apparent mass coefficient, given by

$$
m_{A p p}=K_{A p p} \pi \rho_{\infty} D_{0}^{3}
$$

$$
K_{\text {App }}=T[0,0.035,0.070]
$$

\footnotetext{
$\S$ The trim parachute total angles of attack are $16.56^{\circ}$ for the Boundary 1 curve, $8.90^{\circ}$ for the Nominal curve, and $6.81^{\circ}$ for the Boundary 2 curve.
} 
The parameter $T[0,0.035,0.070]$ is a random number with triangular distribution whose lower limit is 0 , its mode is 0.035 , and its upper limit is 0.070 . A new value of $T$ is determined for each Monte Carlo trial. Note that the use of $T$ makes $m_{A p p}$ a perturbed parameter. The range of values for $K_{A p p}$ was selected after considering those used in reference 20 , and the apparent mass discussion in course notes by S. Lingard. "In the simulation the apparent mass is subject to the force of gravity - an undesired effect since the apparent mass is only intended to generate inertial forces . To counteract the force of gravity on the apparent mass an opposite buoyancy force vector, $\mathbf{F}_{B}$, of magnitude

$$
F_{B}=m_{\text {App }} g_{\text {Mars }}
$$

(where $g_{\text {Mars }}$ is the local acceleration of gravity) acts on the parachute's center of mass. The apparent mass model becomes active in the simulation when the parachute reaches its first full inflation, and remains active thereafter (i.e., $t \geq t_{F I}$ ).

The approach described here to model the apparent mass is highly simplified. See section V.C for recommendations regarding improvements to this model.

\section{K. Main Landing Engines Interaction}

The plumes of the main landing engines (MLE) can disturb the flow field experienced by the parachute. The Main Landing Engines Interaction (MLEI) model accounts for this interaction by defining a time-varying parameter, $K_{M L E I}$, used to as a multiplier for the static aerodynamic coefficients. The value of $K_{M L E I}$ depends on: the location of the parachute with respect to the descent stage center of mass as shown in figure 13, the sum total thrust level of the MLE ( $T_{M L E}$ ), the dynamic pressure at the parachute, the nominal area of the parachute, the Nominal drag coefficient of the parachute, and a thrust scaling factor $\left(\eta_{M L E I}\right)$. The MLEI model becomes active at the time MLE purging starts and remains active through the remainder of the EDL sequence.

The volume within which the MLE interaction occurs is shown in figure 13. This volume is a cylinder of radius $r_{M L E I}$ and height $h_{\text {MLEI }}\left(r_{M L E I}=80 \mathrm{~m}, h_{\text {MLEI }}=800 \mathrm{~m}\right)$. One of the ends of this cylinder is centered at the parachute apex. The cylinder axis of symmetry is parallel to, and in the same direction as, the airspeed vector of the parachute's center of mass, $\mathbf{V}_{P, \infty}$. The MLE interaction will depend on whether the center of mass of the descent stage is inside or outside this cylinder. Two quantities describe the position of the descent stage center of mass with respect to the cylinder as shown in figure 13: $r_{P, D S}$ and $h_{P, D S}$. These quantities can be calculated from:

$$
\begin{gathered}
r_{P, D S}=\frac{\left|\mathbf{V}_{P, \infty} \times \mathbf{R}_{P, D S}\right|}{\left|\mathbf{V}_{P, \infty}\right|} \\
h_{P, D S}=\frac{\mathbf{V}_{P, \infty} \cdot \mathbf{R}_{P, D S}}{\left|\mathbf{V}_{P, \infty}\right|}
\end{gathered}
$$

where $\mathbf{R}_{P, D S}$ is the vector from the apex of the parachute to the center of mass of the descent stage as shown in figure 13. Note that $r_{P, D S}$ is always positive, but $h_{P, D S}$ can be either positive or negative. The value of $K_{M L E I}$ is then calculated as follows:

$$
\begin{gathered}
\text { If } r_{P, D S}>r_{M L E I} \text { or } h_{P, D S}>h_{M L E I} \text { or } h_{P, D S}<0 \text { then } \\
K_{M L E I}=1
\end{gathered}
$$

(descent stage center of mass is outside the cylinder)

$$
\begin{gathered}
\text { else } \\
K_{M L E I}=1-\eta_{M L E I} \frac{T_{M L E}}{q_{\infty} S_{0}\left(C_{D_{0}}\right)_{\text {Nominal }}}
\end{gathered}
$$

(descent stage center of mass is inside the cylinder)

endif

\footnotetext{
` Lingard, S., “Aerodynamics 2 (Unsteady),” Lecture notes presented at the Parachute Systems Technology Short Course, U.S. Army Yuma Proving Ground, May 12-16, 2008.
}

American Institute of Aeronautics and Astronautics 


$$
\text { If } K_{M L E I}<0.02 \text { then } K_{M L E I}=0.02 \text { endif }
$$

(limits the minimum value of $K_{\text {MLEI }}$ to 0.02 )

where $\eta_{M L E I}$ is a scaling factor controlling the magnitude of the MLE interaction. The value of $\eta_{M L E I}$ was set at 0.3075. Note that a minimum value for $K_{\text {MLEI }}$ has been enforced. The possible range for $K_{\text {MLEI }}$ is $0.02 \leq K_{\text {MLEI }} \leq 1$. The static aerodynamic coefficients of the parachute are multiplied by $K_{\text {MLEI }}$ before using them to calculate the aerodynamic forces and moments on the parachute.

The MLEI model was included in the simulation to address concerns regarding backshell re-contact with the separated descent stage and/or rover, either shortly after separation during MLE throttle-up, or long after separation. The model is derived from conservation of momentum principles. However, not enough data are available to assess the validity of its physics and to properly tune the model (i.e., for selecting values of $\eta_{\text {MLEI }}, h_{\text {MLEI }}$, and $r_{\text {MLEI }}$ ). In the absence of sufficient knowledge regarding this model, the simulation approach was to bound the problem by incorporating a large interaction cylinder, and exercising the simulation both with and without the MLEI model to assess the short- and long-term re-contact risks.

\section{Offloading}

Experimental data from reference 21 indicates that a sudden offloading of the parachute due to a step reduction in payload mass (i.e., lander and/or descent stage separation) results in a temporary reduction in the drag area of the parachute and backshell combination. Analyses indicated that this reduction in drag area could not be accounted for by the modeled parachute apparent mass (section III.J). Thus, to account for this temporary reduction in drag area, the offloading model described here was created and implemented in the simulation. This model was created by reanalyzing the data in reference 21 for MSL. Thus this model is not general; application to other spacecraft would require reanalysis of the source data in reference 21.

The parachute offloading model takes the form of a time-dependent nondimensional parameter, $K_{\text {Off }}$, used as a multiplier for the parachute and backshell static aerodynamic coefficients. This multiplier becomes active at the time of descent stage separation from the backshell, $t=t_{S e p, D S}$. The offloading multiplier, $K_{\text {Off }}$, is calculated from

$$
K_{\text {Off }}=1-\left(1-\xi_{\text {Min }}\right) \exp \left[-\left(t-t_{\text {Sep }, D S}\right) / \tau_{\text {Off }}\right]
$$

where $\xi_{\text {Min }}=0.793$ and $\tau_{\text {Off }}=1.965 \mathrm{~s}$. Both $t$ and $t_{\text {Sep,DS }}$ must be entered in seconds in equation (30). A plot of

$K_{\text {Off }}$ vs. $t-t_{S e p, D S}$ for $0 \mathrm{~s} \leq t-t_{S e p, D S} \leq 6 \mathrm{~s}$ is shown in figure 14. Note that within three seconds of $t_{S e p, D S}, K_{\text {Off }}$ is greater than 0.95 , and within six seconds it is greater than 0.99 .

\section{Models Creation, Implementation, Checkout, and Configuration Control}

During the process of developing the models described herein, several lessons were learned regarding their creation, implementation, checkout, and configuration control. Some of these lessons are listed below.

- The responses (i.e., results) required from the simulation need to be clearly understood. Models created for the simulation should be focused on obtaining accurate and/or conservative values of these responses. Models that do not support these responses in a meaningful way should be considered for deletion or simplification.

- Some models are conservative with respect to some simulation responses, but unconservative with respect to others. For example intentionally overestimating the drag coefficient may be conservative with regards to opening forces, but unconservative with regards to terminal descent. In such situations a risk assessment may need to be conducted to balance the risks throughout the system. Another possibility is to try and separate aspects of the model (or perhaps create separate models) so that conservatism can be tuned into the model(s) to address the risk posture adopted by the project regarding various responses. To continue with the previous example, the drag coefficient may be overestimated in the Mach number range where inflation is expected to occur, but underestimated at the lower Mach numbers associated with terminal descent.

- Models should be clearly documented. This documentation should be sufficient for the model to be implemented with minimal interaction with the person(s) that created and documented the models. The model documentation should have a revision history so that changes made to the models can be traced. 
- After the models are implemented into the simulation, the person(s) that created the models and the person(s) that implemented them in the simulation should work together to verify that the modes have been implemented and function as desired.

- A system for configuration control of the models and their data should be established and used. For models that appear in multiple documents, the governing (ruling) source for the models and/or data should be clearly established.

\section{Model Improvements}

Based on the experience of creating the models described above, implementing them in the simulation, and/or comparing the model predictions to the reconstructed values from the MSL flight data, ${ }^{4}$ several improvements to the parachute system models can be suggested. These improvements are described below.

\section{A. Deployment Time}

The present deployment time model defined by equations (3) to (5) in section III.F is empirical and based on data from previous missions, in particular the Viking BLDT flight tests ${ }^{9-11}$ and Mars landers, ${ }^{13}$ and the Phoenix Mars lander. ${ }^{14}$ This was appropriate because of the similarities in the parachute system and operating conditions among these spacecraft. Reconstruction of the MSL flight data ${ }^{4}$ indicates that the model over-predicted the deployment time. It is possible to create a model that explicitly took into account the mortar system performance, aeroshell deceleration at mortar fire, and other relevant variables to create a physics-based model that could predict the deployment time more accurately.

\section{B. Wind Angles Calculation}

The parachute total angle of attack used as the independent variable in the static aerodynamic coefficient model was calculated in the simulation at the parachute's center of mass. It is reasonable to assume that the parachute's aerodynamic forces are closely related to the wind angles somewhere near the canopy. However, the parachute's center of mass - where the wind angles are currently being calculated - is $7.8 \mathrm{~m}$ upstream of the parachute's skirt (see figure 6). In addition, the parachute's center of mass can change position due to changes in materials, without a concurrent change in the inflated shape of the parachute. Thus the parachute wind angles should be calculated at a fixed geometric location near the canopy, perhaps at the skirt.

The difference between the wind angles calculated at the parachute's center of mass and the skirt was estimated to be less than one degree for MSL. Thus, in the simulation it was decided not to change the location where the wind angles were calculated. However this is not a general conclusion, and the suggested improvement would be relatively simple to implement (it was not done so for the simulation to avoid having to revalidate the already tuned simulation late in its development, and to prevent unintended consequences).

\section{Apparent Mass}

The apparent mass model that was used in the simulation is highly simplified. The apparent mass cannot be accounted for with a single point mass - it has different values depending on the axis, and has both mass and mass moment of inertia components. It is recommended that a more sophisticated apparent mass model be incorporated into the simulation for future use, perhaps using the approach suggested by S. Lingard (see footnote I in section III.J).

\section{Concluding Remarks}

Parachute-related models (see figure 4) were incorporated into the MSL POST2 EDL simulation. These models were kept as simple as possible, considering the overall objectives of the simulation (section I). This paper has described the models to the extent necessary to understand how they work and some of their limitations. In a companion paper, ${ }^{4}$ results from a parachute performance reconstruction using Mars flight data for MSL are presented, and compared to some of the parachute models and simulation discussed here. This comparison indicates that the parachute models and simulation provided a reasonable prediction of the parachute system flight behavior on Mars.

\section{Acknowledgements}

The Mars Science Laboratory mission is directed by the Jet Propulsion Laboratory, California Institute of Technology, under contract to NASA. 


\section{References}

${ }^{1}$ Prakash, R., et al., "Mars Science Laboratory Entry, Descent, and Landing System Overview," IEEE Aerospace Conference, Big Sky, MT, March 1-8, 2008.

${ }^{2}$ Striepe, S. A., Way, D. W., Dwyer, A. M., and Balaram, J., "Mars Science Laboratory Simulations for Entry, Descent, and Landing," Journal of Spacecraft and Rockets, Vol. 43, No. 2, 2006, pp. 311-323.

${ }^{3}$ Way, D. W., Davis, J. L., and Shidner, J. D., "Assessment of the Mars Science Laboratory Entry, Descent, and Landing Simulation," 23 $3^{\text {rd }}$ AAS/AIAA Space Flight Mechanics Meeting (AAS Paper 13-420), Kauai, HI, February 10-14, 2013.

${ }^{4}$ Cruz, J. R., et al., "Reconstruction of the Mars Science Laboratory Parachute Performance and Comparison to the Descent Simulation," 22 ${ }^{\text {nd }}$ AIAA Aerodynamic Decelerator Systems Technology Conference and Seminar (AIAA Paper 2013-1250), Daytona Beach, FL, March 25-28, 2013.

${ }^{5}$ Anon., "Viking Lander "As Built" Performance Capabilities," Martin Marietta Corp. Report, NASA Contract NAS1-9000, 1976.

${ }^{6}$ Rowan, J., Moran, J., and Adams, D. S., "Development and Qualification of the Mars Science Laboratory Mortar Deployment System," $20^{\text {th }}$ AIAA Aerodynamic Decelerator Systems Technology Conference and Seminar (AIAA Paper 2009-2916), Seattle, WA, May 4-7, 2009.

${ }^{7}$ Adams, D. S. and Rivellini, T. P., "Mars Science Laboratory's Parachute Qualification Approach," $20^{\text {th }}$ AIAA Aerodynamic Decelerator Systems Technology Conference and Seminar (AIAA Paper 2009-2913), Seattle, WA, May 4-7, 2009.

${ }^{8}$ Kipp, D., San Martin, M., Essmiller, J., and Way, D., "Mars Science Laboratory Entry, Descent, and Landing Triggers," IEEE Aerospace Conference (IEEEAC Paper 1145 Version 2), Big Sky, MT, March 3-10, 2007.

${ }^{9}$ Dickinson, D., Schlemmer, J., Hicks, F., Michel, F., and Moog, R. D., "Balloon Launched Decelerator Test Program, Post-Flight Test Report, BLDT Vehicle AV-1,” NASA CR-112176, 1972.

${ }^{10}$ Dickinson, D., Schlemmer, J., Hicks, F., Michel, F., and Moog, R. D., "Balloon Launched Decelerator Test Program, Post-Flight Test Report, BLDT Vehicle AV-2,” NASA CR-112177, 1972.

${ }^{11}$ Dickinson, D., Schlemmer, J., Hicks, F., Michel, F., and Moog, R. D., "Balloon Launched Decelerator Test Program, Post-Flight Test Report, BLDT Vehicle AV-4,” NASA CR-112179, 1972.

${ }^{12}$ Moog, R. D., and Michel, F. C., "Balloon Launched Viking Decelerator Test Program Summary Report," NASA CR-112288, 1973

${ }^{13}$ Ingoldby, R. N., et al., "Entry Data Analysis for Viking Landers 1 and 2 - Final Report,” NASA CR-159388, 1976.

${ }^{14}$ Desai, P. N., Prince, J. L., Queen, E. M., Cruz, J. R., and Grover, M. R., "Entry, Descent, and Landing Performance of the Mars Phoenix Lander," AIAA/AAS Astrodynamics Specialist Conference and Exhibit, Honolulu, HI, August 18-21, 2008.

${ }^{15}$ Witkowski, A., Kandis, M, and Adams, D. S., "Mars Scout Phoenix Parachute System Performance," $20^{\text {th }}$ AIAA Aerodynamic Decelerator Systems Technology Conference and Seminar (AIAA Paper 2009-2907), Seattle, WA, May 4-7, 2009.

${ }^{16}$ Adams, D. S., Witkowski, A., and Kandis, M., "Phoenix Mars Scout Parachute Flight Behavior," 2011 IEEE Aerospace Conference (IEEEAC Paper 1534, Version 10), Big Sky, MT, March 5-12, 2011.

${ }^{17}$ Reichenau, D. E. A., "Aerodynamic Characteristics of Disk-Gap-Band Parachutes in the Wake of Viking Entry Forebodies at Mach Numbers from 0.2 to 2.5," AEDC-TR-72-73, 1972

${ }^{18}$ Bendura, R. J., et al., "Flight Tests of Viking Parachute System in Three Mach Number Regimes, Part II - Parachute Test Results," NASA TN D-7734, 1974.

${ }^{19}$ Cruz, J.R., et al., "Wind Tunnel Testing of Various Disk-Gap-Band Parachutes," $17^{\text {th }}$ Aerodynamic Decelerator Systems Technology Conference and Seminar (AIAA Paper 2003-2129), Monterey, CA, May 19-22, 2003.

${ }^{20}$ Whitlock, C. H., Poole, L. R., and Talay, T. A., "Postflight Simulation of Parachute Deployment Dynamics of Viking Qualification Flight Tests," NASA TN D-7415, 1973.

${ }^{21}$ Lang, J. R., "Free-Flight Test Results of Scale Models Simulating Viking Parachute/Lander Staging," TR-3720386, Martin Marietta Corp., Denver Division, December 1973.

\section{Appendix: Area Oscillations Model Equations}

The equations used in the calculations to obtain the area oscillations multiplier, $K_{A O M}$, as described in section III.G are given below. The data used to tune this model were obtained from the Viking BLDT AV-4 flight test ${ }^{11}$ and the Phoenix Mars flight. ${ }^{14-16}$ The variable $M$ is the Mach number. The variable $M_{F I}$ is the Mach number at full inflation. Because of interactions between the area oscillations model and the elastic modes of the parachute system, unrealistic values of the Mach number can be obtained at the parachute's center of mass due to rapid motion of the parachute. Thus, the values of $M_{F I}$ and $M$ used in the area oscillations model should be those for the center of mass of the aeroshell, not those calculated at the parachute's center of mass. The model should not be used for Mach numbers higher than $M_{\text {Init }}$. 
Constants used in the area oscillations model.

\begin{tabular}{|l|l|}
\hline Constant & Value \\
\hline$n_{A O M}$ & 3 \\
\hline$K_{H F_{1}}$ & 0.20 \\
\hline$K_{H F_{2}}$ & 0.15 \\
\hline$\omega_{\text {Min }}$ & $2 \pi / 12 \approx 0.524 \mathrm{rad} / \mathrm{s}$ \\
\hline$M_{\text {Init }}$ & 2.057 \\
\hline$M_{\text {Final }}$ & 1.40 \\
\hline$E_{\text {Max }}$ & 0.59 \\
\hline$\tau_{\text {High }}$ & 1.08 \\
\hline$\tau_{\text {Low }}$ & 1.00 \\
\hline
\end{tabular}

$$
\begin{gathered}
\lambda=\frac{\ln 2}{M_{\text {Init }}-M_{\text {Final }}} \\
K_{\text {High }}=15.9474-6.5617 M_{F I} \\
K_{\text {Low }}=2.43032+0.787402 M_{F I}
\end{gathered}
$$

$R_{i}=$ independent $U[0,1)$ for every $i=1$ to 6

values for $R_{i}$ 's calculated once per Monte Carlo trial

$$
\begin{gathered}
R_{S}=\frac{1}{\sum_{i=1}^{6} R_{i}} \\
K_{i}=R_{S} R_{i} \text { for } i=1 \text { to } 6 \\
\omega_{i}=\pi\{U[0,1)+(i-1)\}+\omega_{\text {Min }} \text { for every } i=1 \text { to } 6 \\
U[0,1) \text { is independent for every } i
\end{gathered}
$$

values for $\omega_{i}$ 's calculated once per Monte Carlo trial units of $\omega_{i}: \mathrm{rad} / \mathrm{s}$

$$
\begin{aligned}
& \psi_{i}=2 \pi U[0,1) \text { for every } i=1 \text { to } 6 \\
& U[0,1) \text { is independent for every } i
\end{aligned}
$$

values for $\psi_{i}$ 's calculated once per Monte Carlo trial units of $\psi_{i}: \operatorname{rad}$ 


$$
\begin{aligned}
& \omega_{H F_{1}}=\pi\{7 U[0,1)+6\}+\omega_{M i n} \\
& \omega_{H F_{2}}=\pi\{7 U[0,1)+13\}+\omega_{M i n}
\end{aligned}
$$

$U[0,1)$ is independent for $\omega_{H F_{1}}$ and $\omega_{H F_{2}}$

values for $\omega_{H F_{1}}$ and $\omega_{H F_{2}}$ calculated once per Monte Carlo trial units of $\omega_{\mathrm{HF}_{1}}$ and $\omega_{\mathrm{HF}_{2}}: \mathrm{rad} / \mathrm{s}$

$t_{\text {shift }}=t-t_{F I}$ where $t$ is the lowest value of $t>t_{F I}$ for which:

$$
\begin{gathered}
\left\{\sum_{i=1}^{6} K_{i} \sin ^{n_{A O M}}\left[\omega_{i}\left(t-t_{F I}\right)+\psi_{i}\right]\right\}=0 \\
\text { and its derivative } \\
\frac{d}{d t}\left\{\sum_{i=1}^{6} K_{i} \sin ^{n_{A O M}}\left[\omega_{i}\left(t-t_{F I}\right)+\psi_{i}\right]\right\}= \\
n_{\text {AOM }} \sum_{i=1}^{6} \omega_{i} K_{i} \sin ^{n_{A O M}-1}\left[\omega_{i}\left(t-t_{F I}\right)+\psi_{i}\right] \cos \left[\omega_{i}\left(t-t_{F I}\right)+\psi_{i}\right]<0
\end{gathered}
$$

At this point all constants have been determined, and the calculations proceed as a function of time for $t>t_{F I}$.

$$
\begin{gathered}
S_{6}(t)=\sum_{i=1}^{6} K_{i} \sin ^{n_{A O M}}\left[\omega_{i}\left(t+t_{\text {shift }}-t_{F I}\right)+\psi_{i}\right] \\
T_{1}(t)=S_{6}(t)-K_{H F_{1}} \sin ^{n_{A O M}}\left[\omega_{H F_{1}}\left(t-t_{F I}\right)\right]-K_{H F_{2}} \sin ^{n_{A O M}}\left[\omega_{H F_{2}}\left(t-t_{F I}\right)\right] \\
\text { If } T_{1}(t)>0 \text { then } \\
T_{2}(t)=1+K_{H i g h} T_{1}(t)\left\{\exp \left[\lambda\left(M-M_{\text {Final }}\right)\right]-1\right\} \\
T_{3}(t)=1+E_{\text {Max }}\left(1-\exp \left\{-\tau_{\text {High }}\left[T_{2}(t)-1\right]\right\}\right) \\
\quad \operatorname{else} \\
T_{2}(t)=1+K_{\text {Low }} T_{1}(t)\left\{\exp \left[\lambda\left(M-M_{\text {Final }}\right)\right]-1\right\} \\
T_{3}(t)=\exp \left\{\tau_{\text {Low }}\left[T_{2}(t)-1\right]\right\} \\
\operatorname{endif}
\end{gathered}
$$

perform the above conditional evaluation and appropriate calculations at every time step

$$
\text { If } M \geq M_{\text {Final }} \text { then } K_{A O M}(t)=T_{3}(t) \text { else } K_{A O M}(t)=1 \text { endif }
$$

perform the above conditional evaluation and appropriate assignment at every time step

\footnotetext{
\# All quantities with the subscript " $H F$ " are related to the high-frequency terms shown in equation (A12).
} 
Table 1. Key Geometric Parameters of the MSL Parachute System

\begin{tabular}{|c|c|c|c|}
\hline Item & Symbol & Value & Comments \\
\hline $\begin{array}{l}\text { Nominal (reference) parachute } \\
\text { diameter }\end{array}$ & $D_{0}$ & $21.348 \mathrm{~m}+(0.2 \mathrm{~m} \cdot U[0,1)-0.1 \mathrm{~m})$ & $\begin{array}{l}\text { The unperturbed value } \\
(21.348 \mathrm{~m}) \text { is that of the flight } \\
\text { unit parachute. Random } \\
\text { portion is for use in Monte } \\
\text { Carlo trials. }\end{array}$ \\
\hline $\begin{array}{l}\text { Nominal (reference) parachute } \\
\text { area }\end{array}$ & $S_{0}$ & $S_{0}=\pi D_{0}^{2} / 4$ & $\begin{array}{l}\text { Depends on perturbed value of } \\
D_{0} . \text { Unperturbed value: } \\
S_{0}=357.94 \mathrm{~m}^{2} .\end{array}$ \\
\hline $\begin{array}{l}\text { Nominal (reference) parachute } \\
\text { diameter used in the } \\
\text { calculation of } F_{F I, \text { Des }} \text { only }\end{array}$ & $\left(D_{0}\right)_{\text {Des }}$ & $21.50 \mathrm{~m}$ & No perturbation. \\
\hline $\begin{array}{l}\text { Nominal (reference) parachute } \\
\text { area used in the calculation of } \\
F_{F I, \text { Des }} \text { only }\end{array}$ & $\left(S_{0}\right)_{\text {Des }}$ & $363.05 \mathrm{~m}$ & $\begin{array}{l}\text { Calculated using the equation: } \\
\left(S_{0}\right)_{D e s}=\pi\left(D_{0}\right)_{D e s}^{2} / 4\end{array}$ \\
\hline $\begin{array}{l}\text { Unstretched (as-built) length } \\
\text { of the triple bridle legs (each) }\end{array}$ & $L_{T B L}$ & $1.385 \mathrm{~m}$ & See figure 6. \\
\hline $\begin{array}{l}\text { Distance between the triple } \\
\text { bridle confluence point and } \\
\text { attachment points on the } \\
\text { aeroshell (unstretched, as-built } \\
\text { triple bridle legs) }\end{array}$ & $H_{T B}$ & $1.349 \mathrm{~m}$ & See figure 6. \\
\hline Single riser length & $\overline{L_{R}}$ & $7.546 \mathrm{~m}$ & See figure 6. \\
\hline
\end{tabular}

Notes:

- The quantity $U[0,1)$ is a random variable with uniform distribution in the interval between 0 (inclusive) and 1 (not inclusive). Unless specifically called for, the value of $U[0,1)$ is not reused. 
Table 2. As-built key geometric parameters of the MSL parachute.

\begin{tabular}{|c|c|c|}
\hline Parameter & Value & \\
\hline Nominal (reference) diameter, $D_{0}(\mathrm{~m})$ & 21.348 & \\
\hline $\begin{array}{l}\text { Disk diameter, } D_{D}(\mathrm{~m}) \\
{\left[D_{D} / D_{0}\right]}\end{array}$ & $\begin{array}{r}15.447 \\
{[0.724]}\end{array}$ & \\
\hline $\begin{array}{l}\text { Band diameter, } D_{B}(\mathrm{~m}) \\
{\left[D_{B} / D_{0}\right]}\end{array}$ & $\begin{array}{r}15.608 \\
{[0.731]}\end{array}$ & $\frac{P_{V u} \text { or } D_{V c}}{1}$ \\
\hline $\begin{array}{l}\text { Vent diameter (unconstrained), } D_{V u}(\mathrm{~m}) \\
{\left[D_{V u} / D_{0}\right]}\end{array}$ & $\begin{array}{r}1.576 \\
{[0.0738]}\end{array}$ & $D_{D}$ \\
\hline $\begin{array}{l}\text { Vent diameter (constrained), } D_{V_{c}}(\mathrm{~m}) \\
{\left[D_{V_{c}} / D_{0}\right]}\end{array}$ & $\begin{array}{r}1.524 \\
{[0.0714]}\end{array}$ & \\
\hline $\begin{array}{l}\text { Gap height, } H_{G}(\mathrm{~m}) \\
{\left[H_{G} / D_{0}\right]}\end{array}$ & $\begin{array}{r}0.904 \\
{[0.0424]}\end{array}$ & \\
\hline Band height, $H_{B}(\mathrm{~m})$ & 2.580 & $H_{G}$ \\
\hline$\left[H_{B} / D_{0}\right]$ & [0.1209] & $\longrightarrow D_{B} \longrightarrow$ \\
\hline $\begin{array}{l}\text { Suspension lines length, } L_{S}(\mathrm{~m}) \\
{\left[L_{S} / D_{0}\right]}\end{array}$ & $\begin{array}{r}36.578 \\
{[1.713]}\end{array}$ & \multirow{11}{*}{$\begin{array}{l}\text { Parachute constructed shape. } \\
\text { Figure not to scale. }\end{array}$} \\
\hline $\begin{array}{l}\text { Projected diameter, } D_{P}(\mathrm{~m}) \\
{\left[D_{P} / D_{0}\right]}\end{array}$ & $\begin{array}{r}14.944 \\
{[0.700]}\end{array}$ & \\
\hline Nominal (reference) area, $S_{0}\left(\mathrm{~m}^{2}\right)$ & 357.94 & \\
\hline $\begin{array}{l}\text { Disk area, } S_{D}\left(\mathrm{~m}^{2}\right) \\
{\left[S_{D} / S_{0}\right]}\end{array}$ & $\begin{array}{r}187.40 \\
{[0.524]}\end{array}$ & \\
\hline $\begin{array}{l}\text { Gap area, } S_{G}\left(\mathrm{~m}^{2}\right) \\
{\left[S_{G} / S_{0}\right]}\end{array}$ & $\begin{array}{r}44.01 \\
{[0.123]}\end{array}$ & \\
\hline $\begin{array}{l}\text { Band area, } S_{B}\left(\mathrm{~m}^{2}\right) \\
{\left[S_{B} / S_{0}\right]}\end{array}$ & $\begin{array}{c}126.52 \\
{[0.353]}\end{array}$ & \\
\hline $\begin{array}{l}\text { Vent area (unconstrained), } S_{V u}\left(\mathrm{~m}^{2}\right) \\
{\left[S_{V u} / S_{0}\right]}\end{array}$ & $\begin{array}{r}1.95 \\
{[0.0055]}\end{array}$ & \\
\hline $\begin{array}{l}\text { Vent area (constrained), } S_{V c}\left(\mathrm{~m}^{2}\right) \\
{\left[S_{V c} / S_{0}\right]}\end{array}$ & $\begin{array}{r}1.82 \\
{[0.0051]}\end{array}$ & \\
\hline Geometric porosity (unconstrained vent), $\lambda_{g u}(\%)$ & 12.84 & \\
\hline Geometric porosity (constrained vent), $\lambda_{g c}(\%)$ & 12.80 & \\
\hline Number of gores (and suspension lines), $N_{\text {gores }}$ & 80 & \\
\hline
\end{tabular}

Notes:

- Dimensions in this table are, in general, not known to the level accuracy implied by the numbers above. They are presented here with extra significant figures to make them internally consistent.

- Most of the data in this table was provided by Al Witkowski of Pioneer Aerospace.

- Constraint on vent diameter is due to the vent cords.

- As defined here the suspension lines length is the distance from the parachute skirt to the imaginary confluence point the physical suspension lines would reach if they were extended. In actual construction the suspension lines length as defined here consists of both physical suspension lines and risers that collect sets of suspension lines into fewer load paths.

- The projected diameter $D_{P}$ and the ratio $D_{P} / D_{0}$ are estimates. 
Table 3. Nominal Inflated Parachute Mass Properties.

\begin{tabular}{|l|c|c|}
\hline Property & Symbol & Value \\
\hline Mass & $m_{P}$ & $46.826 \mathrm{~kg}$ \\
\hline $\begin{array}{l}\text { Center of mass along the axis of symmetry, downstream from the } \\
\text { suspension lines confluence point }\end{array}$ & $\left(x_{c h u t e}\right)_{C o M}$ & $-27.516 \mathrm{~m}$ \\
\hline Mass moment of inertia about the parachute's axis of symmetry & $\left(I_{x x}\right)_{C o M}$ & $1,140.1 \mathrm{~kg} \cdot \mathrm{m}^{2}$ \\
\hline $\begin{array}{l}\text { Mass moments of inertia about axes perpendicular to the } \\
\text { parachute's axis of symmetry and to each other, with origin at the } \\
\text { parachute's center of mass }\end{array}$ & $\left(I_{y y}\right)_{C o M}$ and $\left(I_{z z}\right)_{C o M}$ & $10,477.0 \mathrm{~kg} \bullet \mathrm{m}^{2}$ \\
\hline
\end{tabular}
Notes:

- The mass of the parachute stated here, $m_{P}$, includes the deployment bag, canopy, suspension lines, suspension lines risers, and half the single riser.

- The parachute axis of symmetry is $x_{\text {chute }}$, with origin at the suspension lines confluence point, positive pointing upstream. As defined here the suspension lines confluence point is the imaginary confluence point the physical suspension lines would reach if they were extended upstream until they met. In actual construction the suspension lines do not physically meet at this point since they are grouped into risers before they reach this point.

- The axes $y_{\text {chute }}$ and $z_{\text {chute }}$ are perpendicular to the parachute axis of symmetry, $x_{\text {chute }}$, and to each other.

- The parachute geometric model used to derive the mass properties in this table is axisymmetric. Thus, the parachute's center of mass is on its axis of symmetry, the mass products of inertia perpendicular to the axis of symmetry are identical, and the mass products of inertia are zero. 


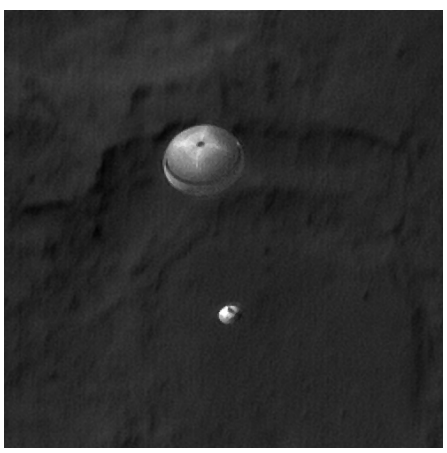

Figure 1. MSL parachute in operation on Mars photographed by the HiRISE camera on the Mars Reconnaissance Orbiter. Image credit: NASA / JPL-Caltech / Univ. of Arizona.

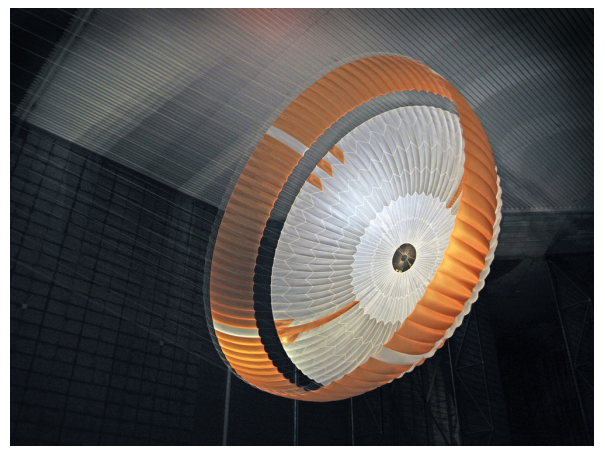

Figure 2. MSL parachute being tested at the National Full-Scale Aerodynamics Complex wind tunnel located at the NASA Ames Research Center in Moffett Field, California. The anti-inversion netting seen attached to the skirt of the canopy was only present for subsonic testing - it was not present on the parachute flown on Mars. Image credit: NASA / JPL-Caltech.

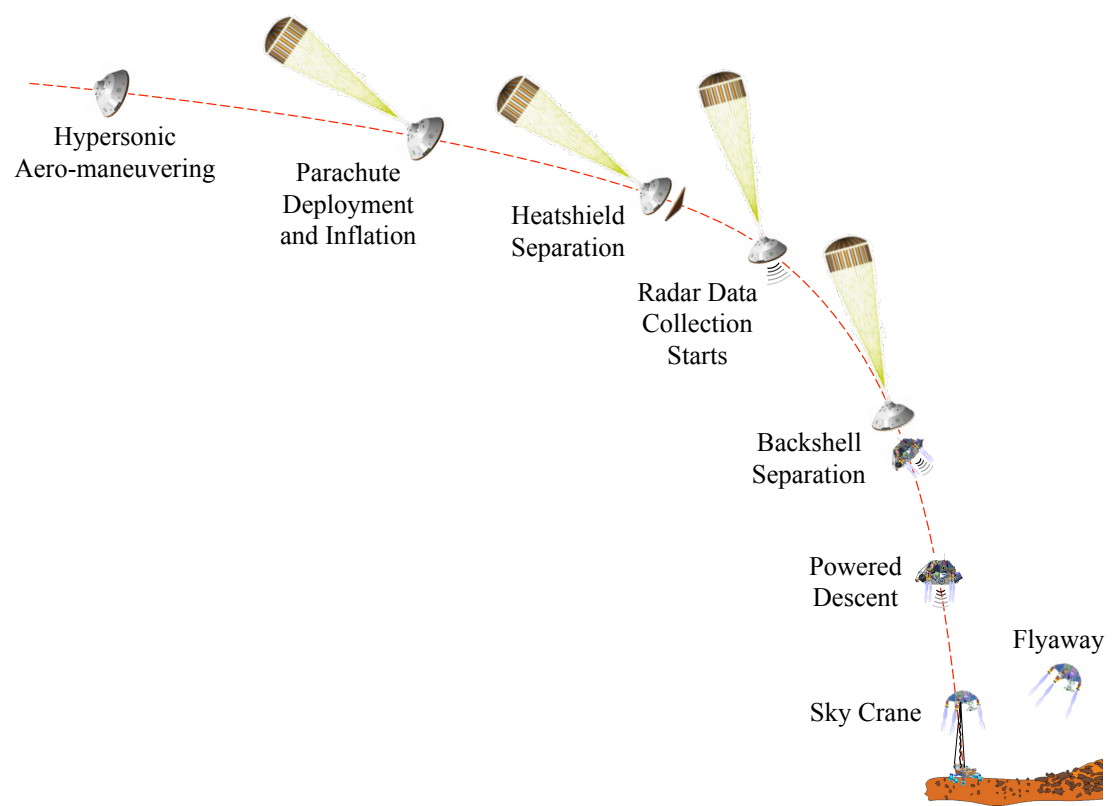

Figure 3. MSL EDL concept of operation from just prior to parachute deployment. Graphics source: JPL-Caltech. 


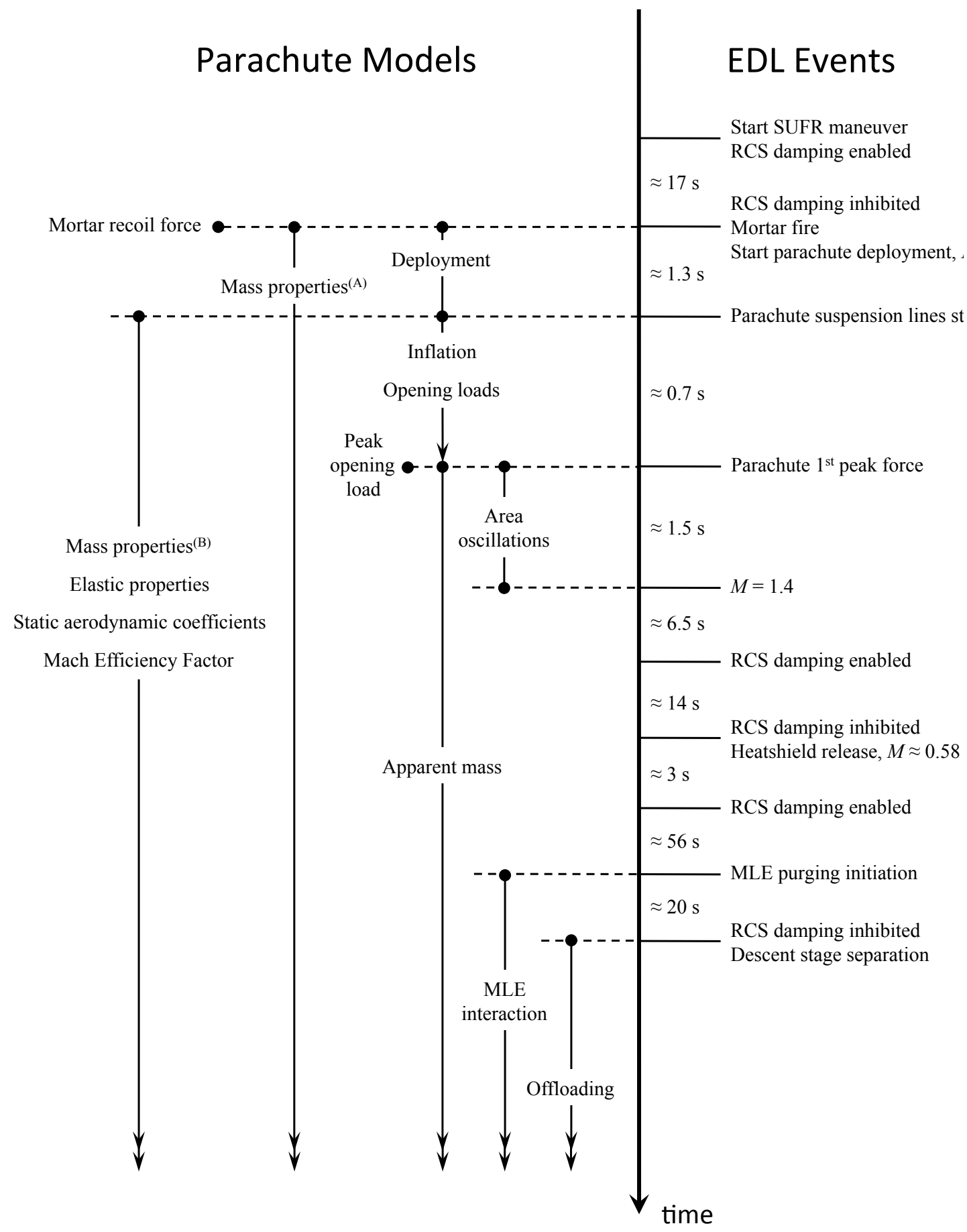

Figure 4. Relationship between the parachute models and EDL events. A closed circle at the beginning or end of a model vertical line indicates that the model is active at that event. A closed circle at the end of a horizontal dashed line indicates a specific time. A single arrow on the end of a model vertical line indicates that the model is active up to, but not including that event. A double arrow on the end of a model vertical line indicates that the model is active until landing. Mass properties ${ }^{(\mathrm{A})}$ are those retained by the aeroshell; Mass properties ${ }^{(\mathrm{B})}$ are those associated with the parachute. See the specific model sections for more details. 


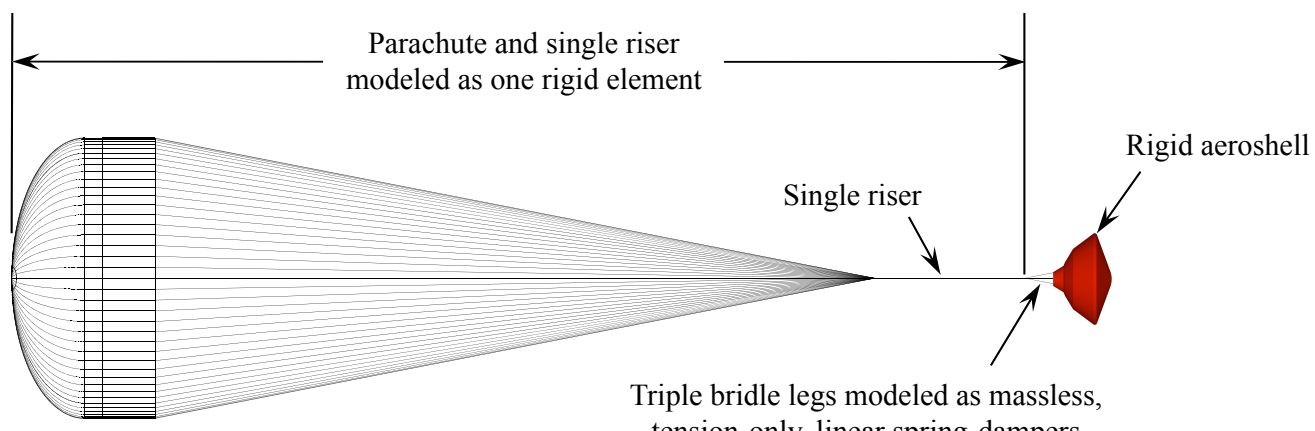
tension-only, linear spring-dampers

Figure 5. Inflated parachute modeling.
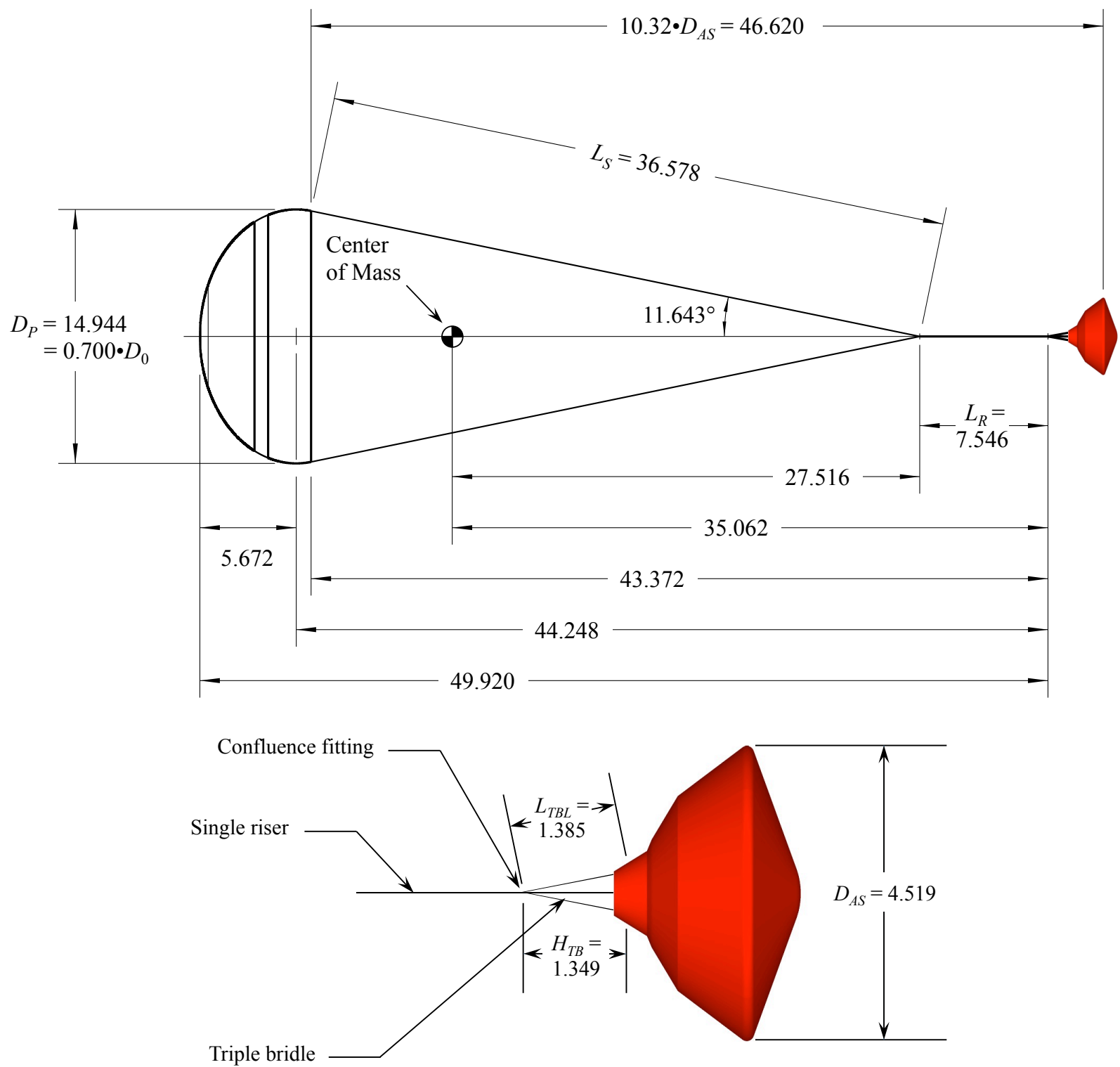

Figure 6. Parachute system dimensions. All linear dimensions in meters. Note that the triple bridle legs attach to the aeroshell inside its outer mold line. Aeroshell graphic by Karl T. Edquist, NASA Langley Research Center. 


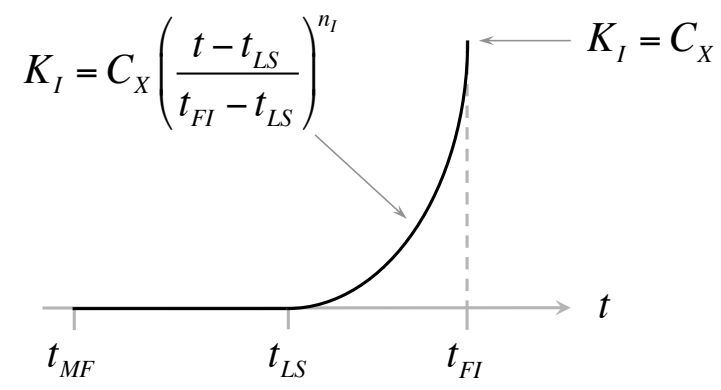

Figure 7. Graphical representation of the inflation multiplier $K_{I}$.

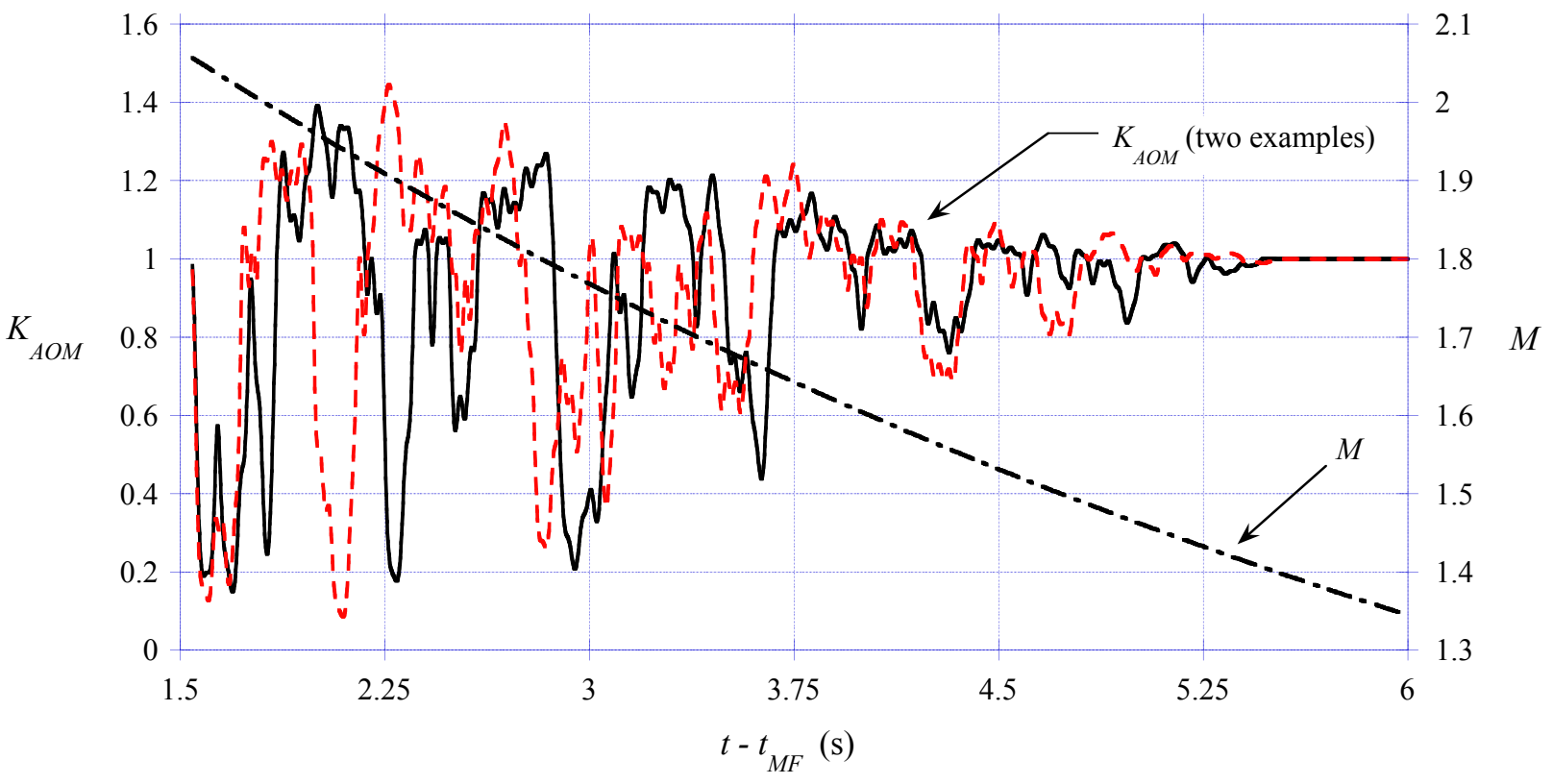

Figure 8. Two examples of the area oscillation multiplier, $K_{A O M}$, vs. time since mortar fire, $t-t_{M F}$, for an assumed Mach number, $M$, time history (Viking BLDT AV-4 test flight ${ }^{11}$ ). 


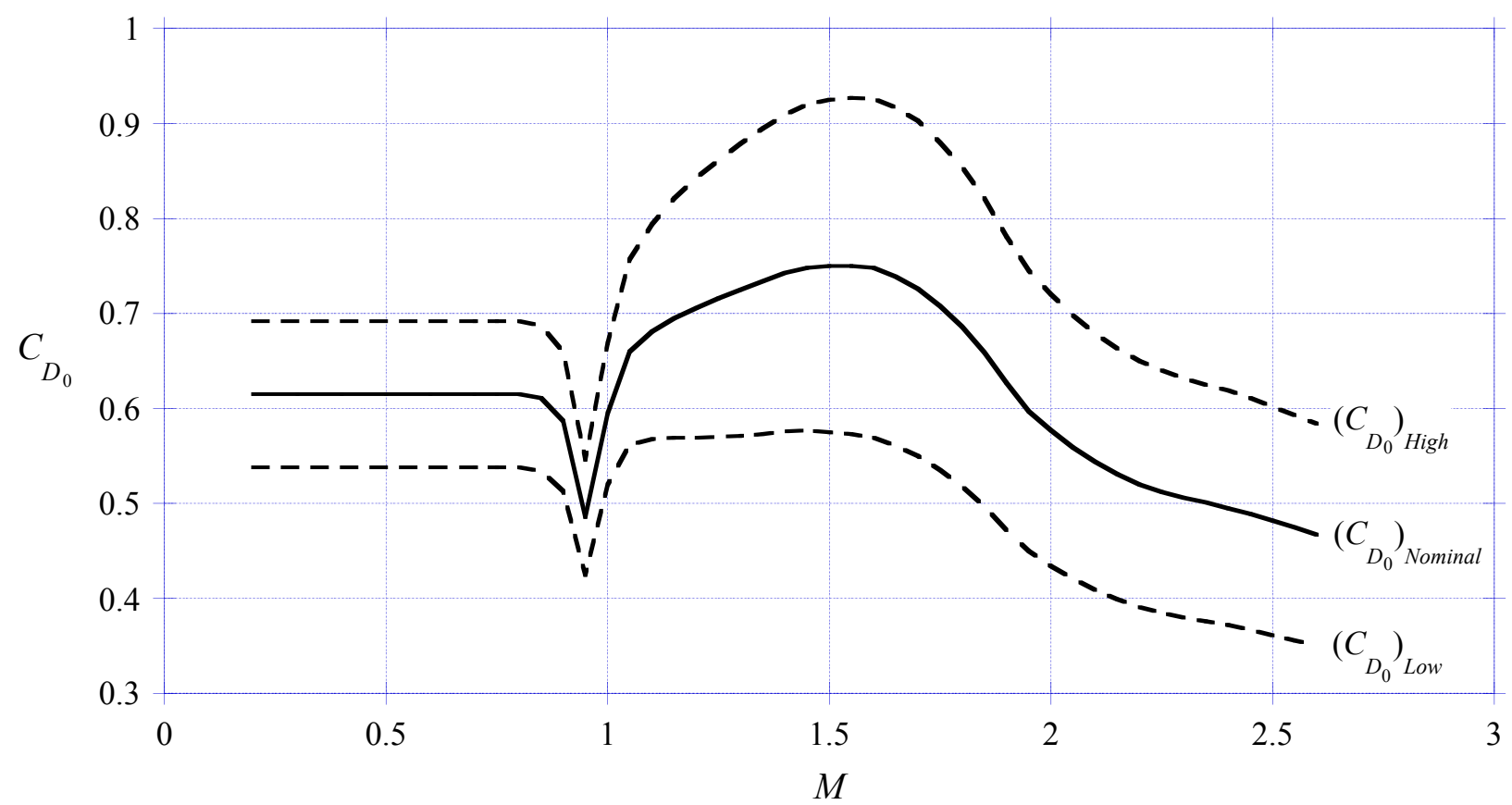

Figure 9. Drag coefficient, $C_{D_{0}}$, model.

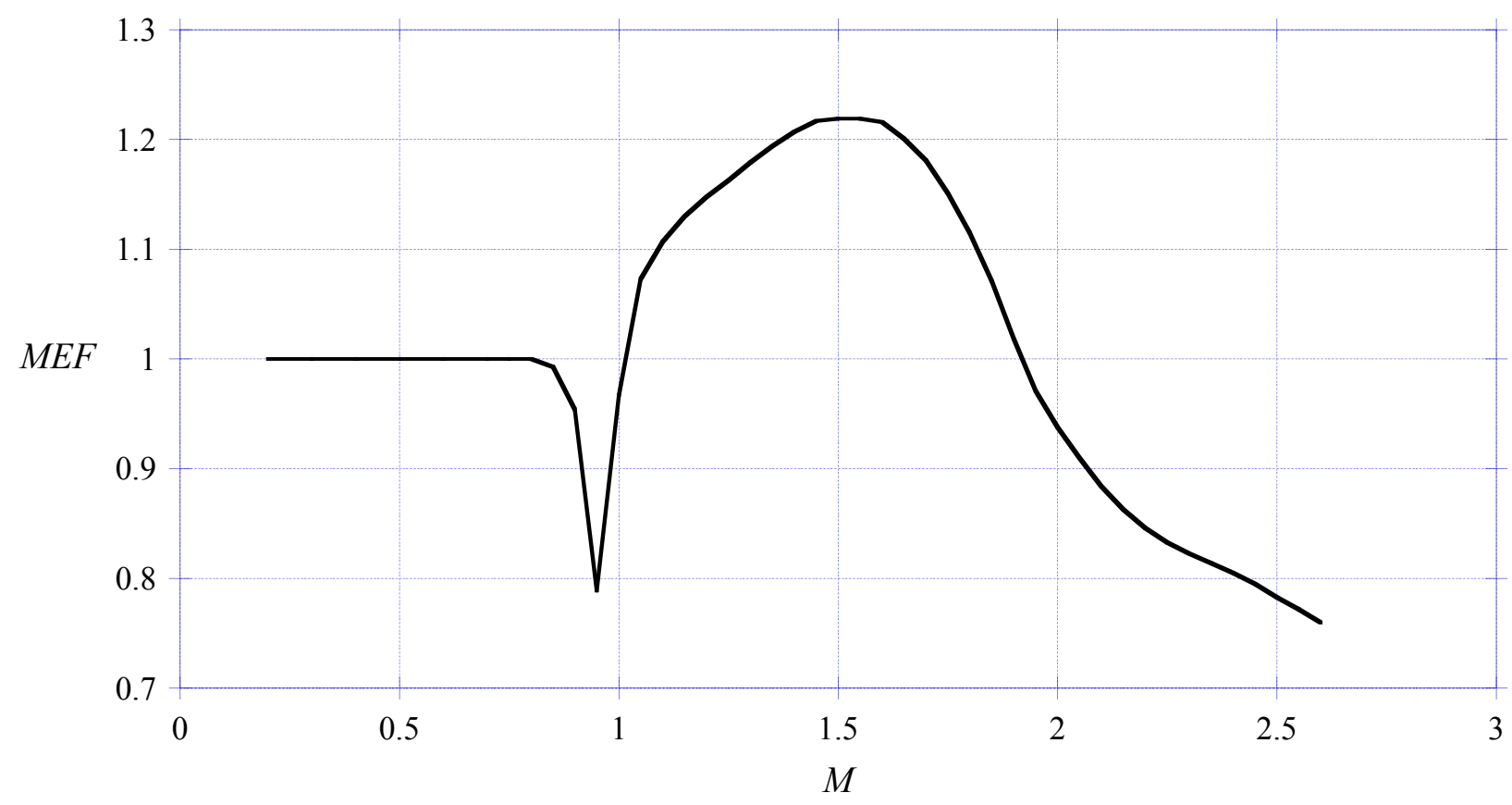

Figure 10. Mach Efficiency Factor, $M E F$, model. 


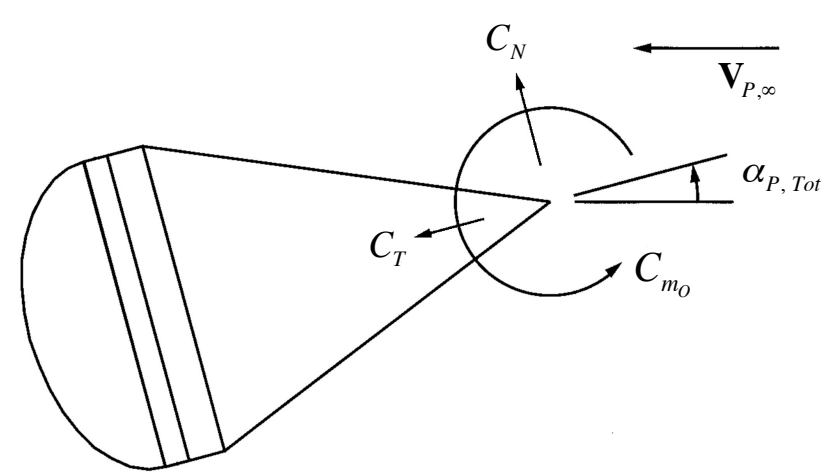

Figure 11. Parachute static aerodynamic coefficients.
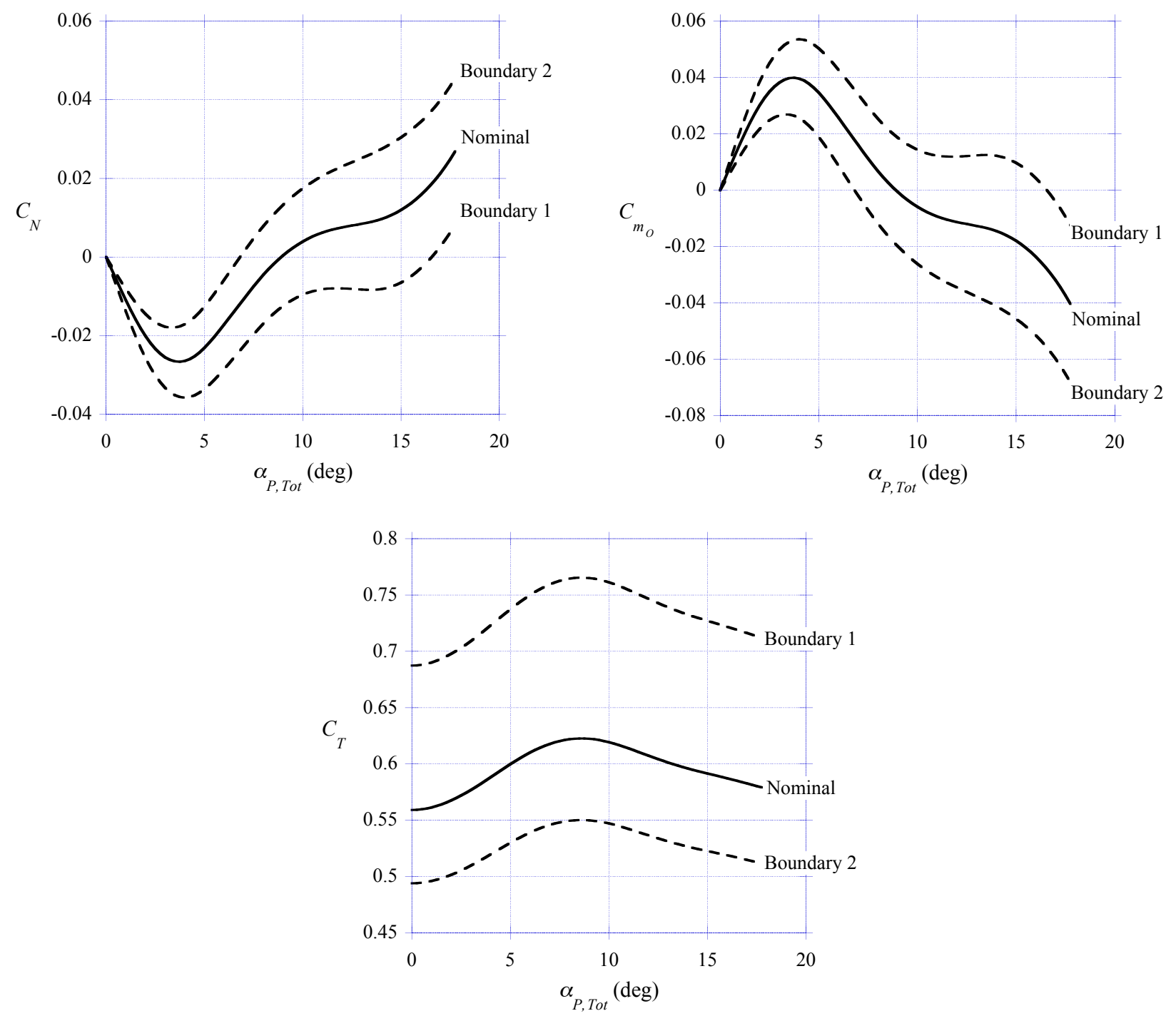

Figure 12. Parachute static aerodynamic coefficients model. The trim parachute total angles of attack are $16.56^{\circ}$ for the Boundary 1 curve, $8.90^{\circ}$ for the Nominal curve, and $6.81^{\circ}$ for the Boundary 2 curve. 


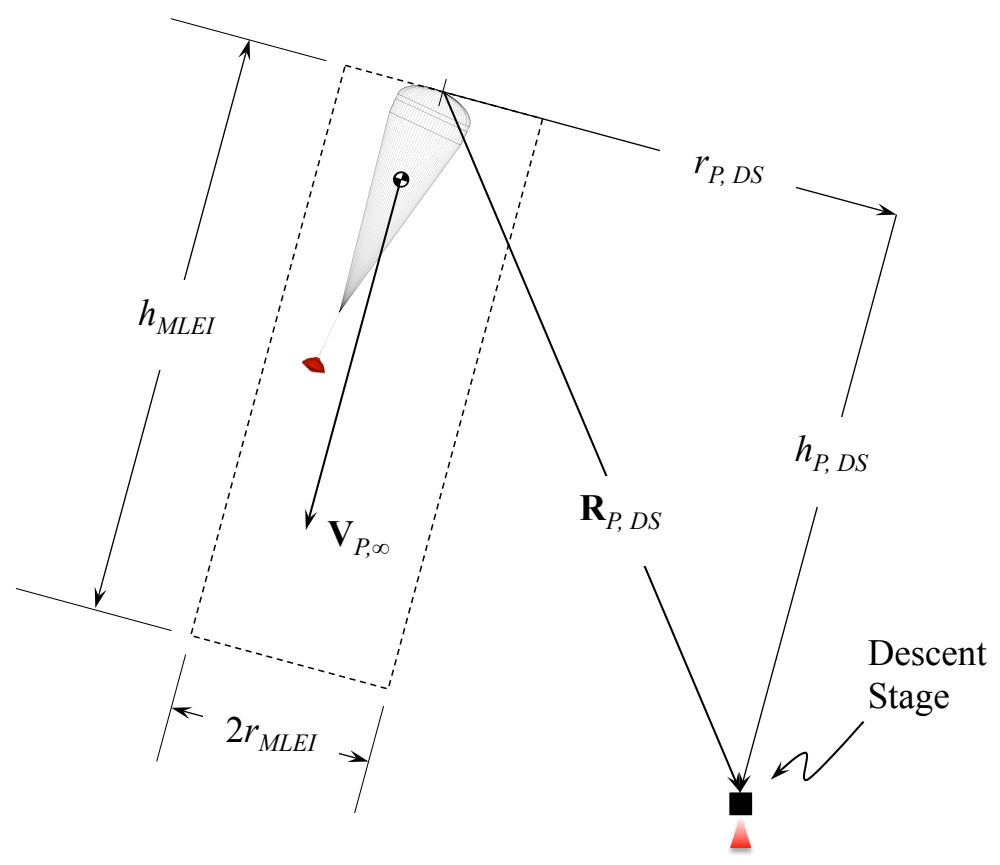

Figure 13. Geometry for the Main Landing Engines Interaction (MLEI) model. As shown here, $h_{P, D S}>0$. Figure not to scale.

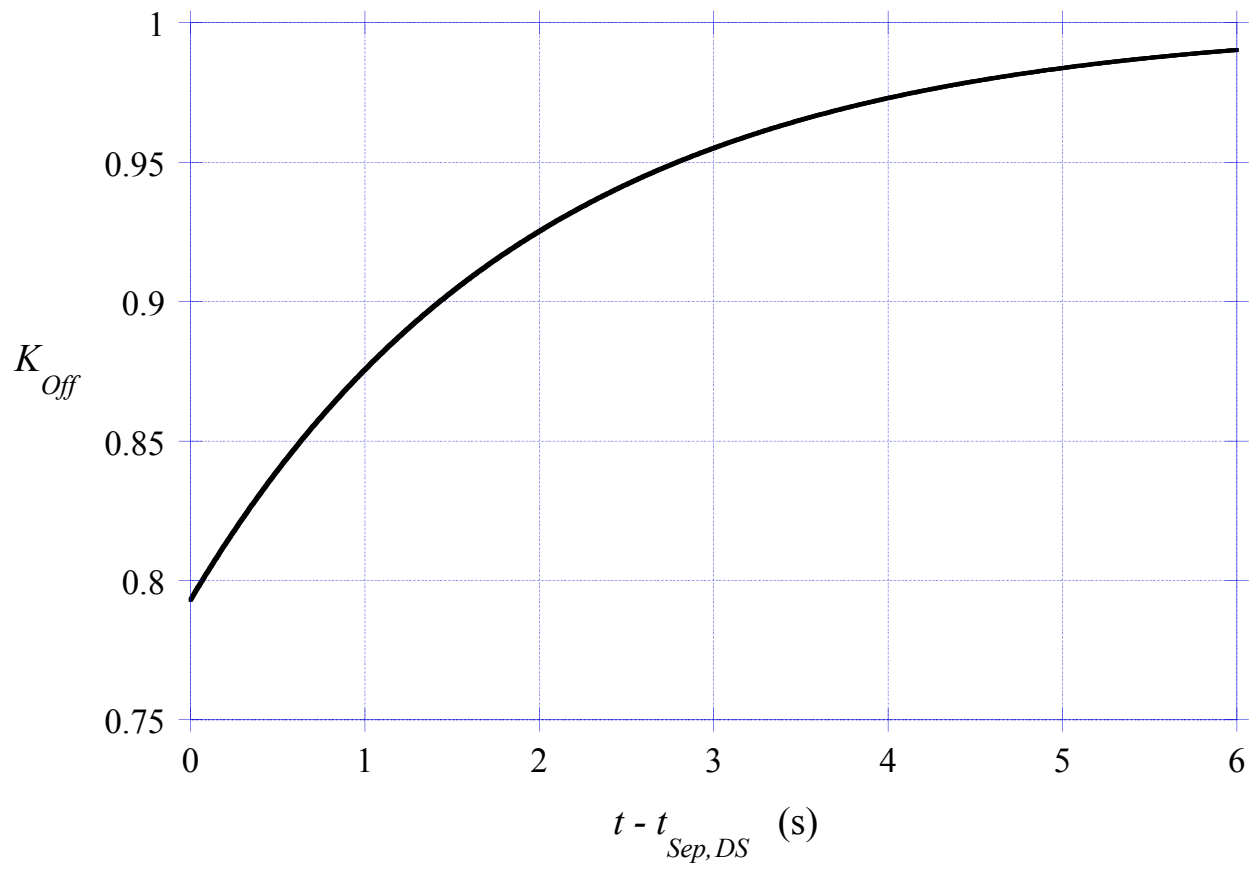

Figure 14. Offloading model multiplier, $K_{\text {Off }}$, vs. time since descent stage separation, $t-t_{S e p, D S}$. 